\title{
Modification of Leech Behavior Patterns by Reserpine-Induced Amine Depletion
}

\author{
Bruce A. O'Gara, Heechin Chae, Lisa B. Latham and W. Otto Friesen \\ Department of Biology and Biodynamics Institute, University of Virginia, Charlottesville, Virginia 22901
}

\begin{abstract}
A single injection of $100 \mu \mathrm{g}$ reserpine into the crop of the medicinal leech, Hirudo medicinalis, reduced CNS serotonin and dopamine levels to less than $1 \%$ of control values within 3 d. High-pressure liquid chromotography- (HPLC) determined CNS serotonin and dopamine levels remained maximally depressed for approximately 1 month following reserpine injection. Subsequently, amine levels recovered slowly, but remained depressed 6 months after reserpine injection. Following reserpine treatment, glyoxylic acid-induced fluorescence or neutral red staining closely mirrored the HPLC-determined time course of amine depletion and recovery. Acute exposure of isolated ganglia to $10 \mu \mathrm{M}$ reserpine for periods up to $6 \mathrm{hr}$ produced a $20-30 \%$ reduction of serotonin and dopamine content. The threshold concentration of reserpine necessary to produce amine depletion was approximately $1 \mu \mathrm{M}$.

We found that reserpine treatment eliminated biting behavior within $4 \mathrm{~d}$ following injection. Biting behavior remained depressed below control levels for approximately 4 months, but returned to control values while CNS serotonin and dopamine levels remained significantly depressed at this time. Unexpectedly, reserpine treatment increased rather than reduced the duration of stimulus-evoked swimming activity. This behavioral change was evident within $3 \mathrm{~d}$ and persisted for approximately 3.5 months.
\end{abstract}

To rapidly restore amine levels in reserpine-treated animals, we bathed intact leeches in pond water containing serotonin, dopamine, or octopamine. We found that biting behavior was restored following reserpine treatment by bathing intact leeches in pond water containing serotonin or dopamine, but not octopamine. Also contrary to expectations, the increase in swim duration was not reversed by bath exposure to serotonin, dopamine, octopamine, or histamine. However, all swimming activity in reserpine-treated leeches was eliminated by the amine antagonist cyproheptadine. We propose that the presence of low levels of amines is critical for the expression of both biting and swimming activity in leeches. However, the minimal levels of amines necessary for the expression of these behaviors are lower for swimming than for biting.

\footnotetext{
Received Jan. 8, 1990; revised Aug. 30, 1990; accepted Sept. 5, 1990.

This work was supported by NIH Grants NS08263 to B.A.O. and NS21778 to W.O.F. We would like to thank Wilson McIvor for assistance in developing the HPLC procedures. We thank Drs. J. D. Angstadt and P. S. Mangan for a critical reading of the manuscript.

Correspondence should be addressed to Bruce O'Gara, Department of Biological Sciences, Barnard College, Columbia University, 3009 Broadway, New York, NY 10027.

Copyright (C) 1991 Society for Neuroscience 0270-6474/91/010096-15\$03.00/0
}

It has been clear for several years that serotonin plays a crucial role in regulating the expression of swimming activity and feeding behavior in the leech. For example, leeches with relatively high concentrations of serotonin in their blood swim more often than leeches with relatively low blood serotonin levels (Willard, 1981). Moreover, increased swimming activity can be induced by injecting serotonin into intact lecches or by exposing as few as 2 ganglia of isolated nerve cords to serotonin. Release of serotonin by prolonged electrical stimulation of the serotonergic Retzius cells also induces swimming. Two additional serotonincontaining neurons, cells 21 and 61 [sometimes termed the dorsolateral (DL) and ventrolateral (VL) serotonin-containing neurons (Marsden and Kerkut, 1969; Lent et al., 1979)], evoke swimming activity even more rapidly and reliably than the Retzius cells when depolarized by current injection (Nusbaum, 1986; Nusbaum and Kristan, 1986). Conversely, when serotonin is functionally removed from the nervous system by pharmacological treatment, swimming does not occur. For example, when the serotonin-containing neurons are ablated from embryonic leeches by treatment with 5,7-dihydroxytryptamine (5,7-DHT), swimming activity is not expressed when these animals mature to the juvenile stage (Glover and Kramer, 1982). However, swimming ability can be restored in these juvenile leeches by application of exogenous serotonin. In another study, depletion of amine neurotransmitters from isolated nerve cords by acute application of reserpine eliminated the expression of swimming activity (Hashemzadeh-Gargari and Friesen, 1989). Finally, swimming activity can also be eliminated from isolated nerve cords by exposure to the amine antagonist cyproheptadine (Hashemzadeh-Gargari and Friesen, 1989). These experiments demonstrate that serotonin acts as a neuromodulator that controls swimming movements in the leech.

Biting behavior has also been shown to be dependent on CNS serotonin levels (Lent and Dickinson, 1984; Lent, 1985; Lent et al., 1989). Both the blood and the CNS of hungry leeches have higher serotonin levels than found in sated leeches (Lent, 1984; Lent et al., 1989). Depletion of serotonin by 5,7-DHT treatment eliminates biting behavior, which can be restored by bathing the intact leech in pond water containing serotonin (Lent and Dickinson, 1984).

One of our research goals is to describe serotonin-induced modifications of neuronal function in the leech that modulate the expression of swimming activity. Although such modifications should be measurable in experiments comparing neuronal function prior to and following serotonin application to the isolated nerve cord, the extent of modulation present in the normal leech due to the presence of endogenous serotonin is unknown and uncontrolled. For example, serotonin levels in the leech CNS may be altered by the stresses of capture and 
dissection. In addition, the chemical, thermal, and tactile stimuli associated with handling are identical with those associated with normal feeding and thus would likely activate serotonin-containing neurons involved in feeding (Lent, 1985). One method of controlling the effects of serotonin is first to deplete serotonin from the intact leech and then to reintroduce known concentrations of serotonin to the isolated nervous system. The effects of these serotonin applications on specific swim-related neurons and synapses can then be examined. This paradigm has been used to show that serotonin increases synaptic fatigue in several inhibitory synapses between swim-related neurons (Friesen et al., 1988).

In some previous work, serotonin was depleted from the leech nervous system with 5,7-DHT (Glover and Kramer, 1982; Lent, 1984). However, there are several problems with using 5,7-DHT for our purposes. First, in adult leeches, 5,7-DHT treatment is difficult because this drug must be injected into the ventral blood sinus that surrounds the nerve cord (Lent, 1984). Second, 5,7DHT only depletes about $50 \%$ of the total serotonin content from the nervous system of adult leeches. Even more importantly, the serotonin-containing swim-gating neurons, cells 21 and 61, show little evidence of serotonin depletion following 5,7-DHT trcatment; in fact, such treated leeches swim normally (Lent, 1985). We sought a technique by which we could simply and reliably produce a profound reduction of serotonin levels in the leech nervous system.

Reserpine inhibits the storage of amines by binding specifically to the amine translocator of storage organelles (reviewed by Shore, 1962; Slotkin, 1974; Giachetti and Shore, 1978; Johnson, 1988). At high concentrations, reserpine also acts as a detergent, thus allowing transmitter efflux due to increased membrane permeability (Zallakian et al., 1982). Reserpine has been previously shown to deplete amines from the leech nervous system by 2 laboratories. First, Marsden and Kerkut (1969) showed that reserpine reduced formaldehyde-induced fluorescence of amine-containing neurons, and second, Webb and Orchard (1980) demonstrated reserpine-induced depletion of octopamine.

In the experiments described here, we characterized the extent and duration of amine depletion induced by injecting reserpine into the crop of the leech Hirudo medicinalis. We also examined the effects of a single injection of reserpine on 2 behaviors known to be dependent on serotonin levels in the leech, biting and swimming. Our results demonstrate that a single injection of $100 \mu \mathrm{g}$ reserpine into the crop causes a greater than $99 \%$ depletion of serotonin and dopamine. Reserpine injection eliminates or reduces biting behavior for a period of approximately 4 months. Biting behavior was restored in reserpine-treated leeches by bath application of serotonin or dopamine, but not octopamine. Unexpectedly, reserpine treatment increased the swim duration evoked by sensory stimulation. In addition, we determined the extent of acute reserpine-induced amine depletion from isolated nerve cords under conditions that have been shown to abolish swimming activity (Hashemzadeh-Gargari and Friesen, 1989).

Some of these results were previously published in abstract form (O'Gara and Friesen, 1988; O'Gara et al., 1989).

\section{Materials and Methods}

Animals, dissection, and drugs

Medicinal leeches, Hirudo medicinalis, were obtained from a commercial supplicr and maintaincd in aquaria at about $18^{\circ} \mathrm{C}$ on a $12: 12$ light: dark cycle for up to $1 \mathrm{yr}$. Leeches used in these studies (except as noted) were fed on ox blood at the end of January and at the end of June. Serotonin (5-hydroxytryptamine creatinine sulfate), dopamine $\mathrm{HCl}$, octopamine $\mathrm{HCl}$, histamine dihydrochloride, and reserpine were obtained from Sigma (St. Louis, MO); cyproheptadine $\mathrm{HCl}$ sesquihydrate was obtained from Aldrich (Milwaukee, WI).

The leech CNS consists of the supraesophageal ganglion and 32 metameric ganglia: 4 are fused to form the subesophageal ganglion; 21 occur as individual, unfused midbody ganglia joined by connectives; and 7 are fused to form the posterior ganglion. Amine neurotransmitters are present in each midbody ganglion within 7 serotonin-containing neurons (see Fig. $4 L$; Lent et al., 1979), within the processes of 2 dopaminecontaining neurons whose somata lie in the anterior nerve roots (Lent et al., 1983), and within 2 octopaminc-containing neurons (Belanger and Orchard, 1986). The subesophageal ganglion contains several additional serotonin-containing neurons (Lent and Dickinson, 1984), as well as the somata of the dopamine-containing neurons (Marsden and Kerkut, 1969). To assay the amine content of leech nervous tissue with high-pressure liquid chromatography (HPLC) or histological methods, chains of midbody ganglia or the cephalic ganglia (combined supraesophageal and subesophageal ganglia) were dissected from adult leeches. To conserve the neurotransmitter content of the nervous system during dissection, a modified leech saline was used that contained no $\mathrm{Ca}^{2+}$ and included elevated $\mathrm{Mg}^{2+}(100 \mathrm{~mm} \mathrm{NaCl}, 4 \mathrm{~mm} \mathrm{KCl}, 10 \mathrm{~mm}$ $\mathrm{MgCl}_{2}, 10 \mathrm{~mm}$ HEPES buffer, adjusted to pH 7.4 with NaOH). Peripheral nerves were severed close to the ganglia, and at each end of the chain, the connectives were severed midway between ganglia. Because the peripheral nerves were severed close to the ganglia, the dopaminecontaining somata in the anterior roots of midbody ganglia were not included in the tissue samples (Lent et al., 1983). Serotonin content of vasofibrous tissue, which is especially prevalent in the wall of the ventral blood sinus (Coggeshall and Yaksta-Sauerland, 1974), was sampled after isolating a 3-segment length of the ventral sinus and determining its mass to the nearest $0.1 \mathrm{mg}$.

The HPLC experiments reported in this paper were conducted during the course of $1 \mathrm{yr}$ (data were obtained in every month except October). Serotonin and dopamine levels in midbody ganglia of untreated control leeches (maintained in the laboratory) varied with the time of year they were assayed (Fig. 1). The highest levels of serotonin were found in January (28.86 $\pm 1.97 \mathrm{pmol} /$ ganglion), and lowest levels were found in July (12.36 $\pm 1.63 \mathrm{pmol} /$ ganglion). A 1 -way analysis of variance (ANOVA) indicated that significant differences cxisted in scrotonin levels over the 1 -yr interval $(p<0.01 ; F=6.14 ; \mathrm{df}=10,138)$. Subsequent analysis indicated these significant differences $(p<0.05)$ : January was significantly different from June, July, August, September, and November; February was significantly different from July. A similar seasonal variation of serotonin levels has been previously described in Hirudo, with reported winter levels 3 times the summer levels (Stenzel and Neuhoff, 1976). The serotonin content of the CNS is dependent on the nutritional status of the leech and is reduced following feeding (Lent et al., 1988). The seasonal rhythm we report was not due to feeding of the animals at opportune times. While it is true that reductions in serotonin levels were evident following the January and June feedings (Fig. 1), these feedings were not responsible for the seasonal rhythm of serotonin levels. This is indicated by the fact that the serotonin levels during February and July (months immediately following a fecding) werc significantly different from each other.

A seasonal variation in neutral red staining (see below) was also evident, with the Retzius cells showing little or no staining in the summer (not shown). Neutral red staining of other serotonin containing neurons (cells 21,61 , and the posterior median cell) showed no obvious seasonality. The seasonal variation of glyoxylic acid-induced fluorescence was not as large as the variation in neutral red staining, though fluorescence appeared more intense in the winter than in the summer.

Our data on the seasonal variation of dopamine levels are not as complete because dopamine content was not assayed during spring and early summer. However, we did find that, in contrast to serotonin, dopamine levels of midbody ganglia (Fig. $1 B$ ) were significantly higher in summer (July-September; $1.68 \pm 0.08 \mathrm{pmol} / \mathrm{ganglion} ; n=58$ ) than in winter (November-February; $1.31 \pm 0.06 \mathrm{pmol} /$ ganglion; $n=48 ; p$ $<0.001 ; t=3.84 ; \mathrm{df}=104)$.

\section{High-pressure liquid chromatography}

HPLC was used to determine serotonin and dopamine levels in normal leeches and to monitor reserpine-induced depletion of these amincs. 

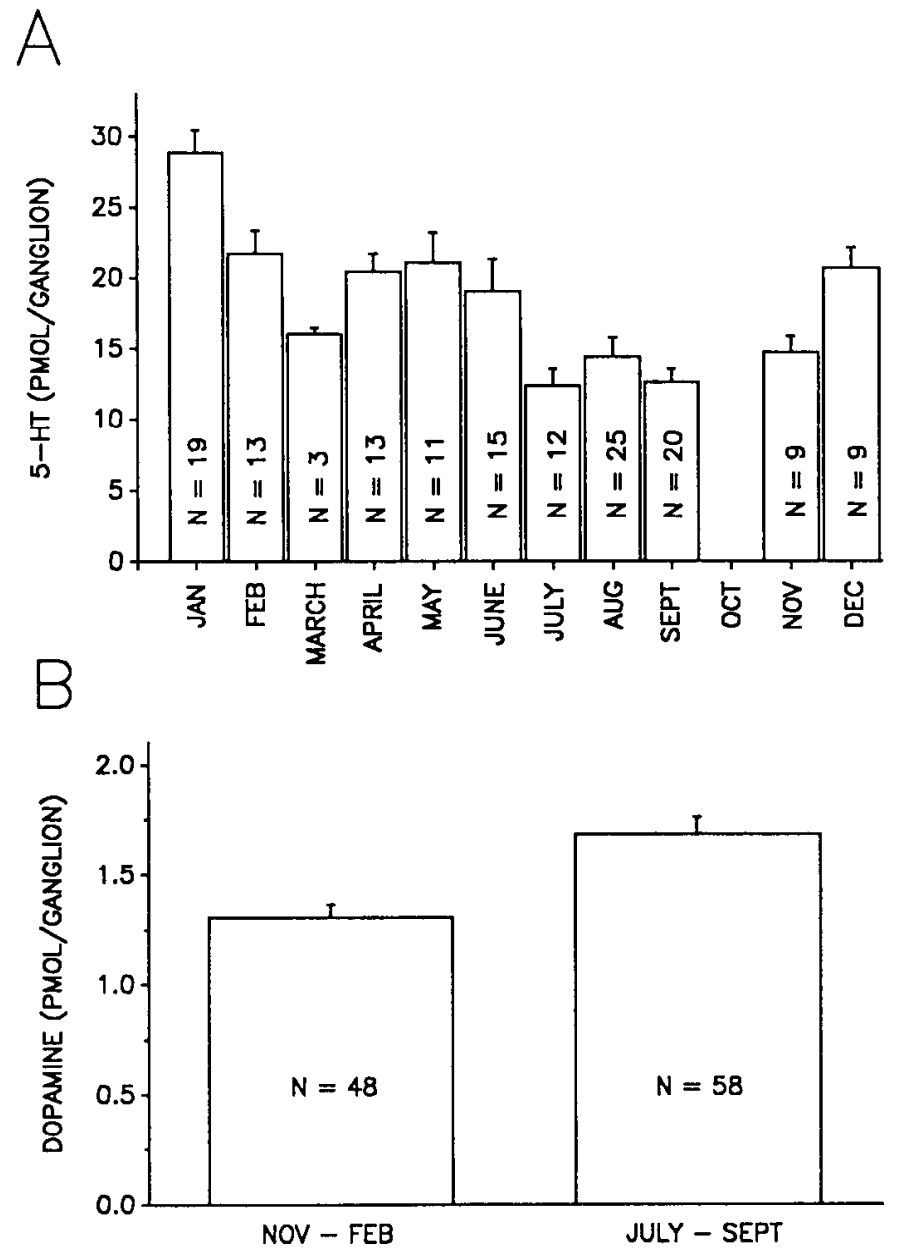

Figure 1. Seasonal variation in serotonin and dopamine content of midbody ganglia. $A$, Serotonin levels. $B$, Dopamine levels. Data for this figure are derived from the normal, untreated leeches also used in the experiments depicted in Figures 3, 4, and 6. The number of leeches assayed for each time period is indicated within the bars. No animals were assayed in October. Error bars represent SEM.

After removal from the leech, tissue to be assayed for amine content by HPLC was placed in $250 \mu \mathrm{l} 0.1 \mathrm{~N}$ perchloric acid in a $1.5-\mathrm{ml} \mathrm{mi-}$ crocentrifuge tube. We found that "pure" water from several sources contained a contaminant that co-eluted with serotonin; hence, Gibco distilled water (Grand Island, NY), which lacked this contaminant, was used in all sample preparation. Samples were frozen and thawed 3 times and then centrifuged at $12,500 \times g$ in a Beckman Microfuge $E$ for 5 min. The supernatant was removed and injected into the HPLC in 20 $\mu \mathrm{l}$ aliquots. A blank tube containing only $0.1 \mathrm{~N}$ perchloric acid was treated identically and was used to assure that the perchloric acid solution was free of contaminants that co-eluted with serotonin. Mean values were obtained from 3-6 injections of each samplc. The HPLC apparatus consisted of a Beckman 100A pump, a Brownlee C-18 guard cartridge, a $4.6 \mathrm{~mm} \times 25 \mathrm{~cm}$ or $4.6 \mathrm{~mm} \times 15 \mathrm{~cm}$ reverse-phase column [BAS, 5- $\mu \mathrm{m}$ RPC-18 $(25 \mathrm{~cm})$, Beckman Ultraspherse $5-\mu \mathrm{m}$ ODS (25 $\mathrm{cm})$, or Phenomenex Ultracarb $5-\mu \mathrm{m}$ ODS $(15 \mathrm{~cm})]$, and an electrochemical detector with its working electrode set at $+0.65 \mathrm{~V}$ above the reference electrode (BAS LC-4A amperometric controller, TL-8A transducer cell, and RE3 electrode). Column temperature was maintained at 35 or $40^{\circ} \mathrm{C}$, and flow rate was $1.5 \mathrm{ml} / \mathrm{min}$. The mobile phase was recycled and had the following composition: $0.15 \mathrm{M}$ monochloroacetic acid, 0.86 M sodium octyl sulfate, $7 \mathrm{~mm}$ EDTA, and 8-12\% acetonitrile. Acetonitrile was periodically added to the mobile phase reservoir to keep retention times relatively constant. To reduce the formation of bubbles in the detector, the mobile phase reservoir was sparged with helium and maintained at $30^{\circ} \mathrm{C}$. The identification of serotonin and dopaminc peaks in the samples was determined by their identical retention times and voltammetry as compared with known standards. Peak areas were determined by a Beckman 427 integrator, which calculated the amount of transmitter present in the sample utilizing previously determined standard curves. Detection limits for both serotonin and dopamine were 25-30 fmol/20- $\mu \mathrm{l} \mathrm{sample.}$

\section{Reserpine treatment}

We sought to develop a method that would easily and reliably deplete amines from the nervous system. We utilized reserpine because it is known to produce profound and prolonged depletion of amines (Shore, 1962; Slotkin, 1974; Giachetti and Shore, 1978; Johnson, 1988). Reserpine was dissolved in $50 \mu \mathrm{l}$ glacial acetic acid and then diluted to the final concentration with normal saline (115 mM NaCl, $4 \mathrm{~mm} \mathrm{KCl}, 1.8$ $\mathrm{mM} \mathrm{CaCl}_{2}, 2 \mathrm{~mm} \mathrm{MgCl}, 10 \mathrm{~mm}$ HEPES buffer, pH 7.4). To measure reserpine-induced amine depletion in intact leeches, reserpine $(100 \mu \mathrm{g}$ in $0.2 \mathrm{ml}$ saline) was injected with a tuberculin syringe through the body wall and into the crop of leeches immobilized with ice-cold saline. The leeches had body weights of $0.5-4 \mathrm{gm}$ (most were in the 1-2-gm range). If the injected reserpine were equally distributed throughout the body, reserpine concentrations would range from approximately 40 to $165 \mu \mathrm{M}$ (largest to smallest body weights, respectively). At fixed times after injection, the cephalic ganglia (supraesophageal and subesophageal ganglia) and midbody ganglia 10-12 were removed from the leech and assayed for dopamine and serotonin content with HPLC. In most preparations, midbody ganglia 2-7 were also removed and processed for glyoxylic acid-induced fluorescence (see below), while midbody ganglia 8 and 9 were stained with neutral red (see below). After reserpine injection, the amine content of the nervous system was assayed from animals killed at 12 -hr intervals for $8 \mathrm{~d}$, then daily through $10 \mathrm{~d}$. After $10 \mathrm{~d}$ postinjection, animals were sampled at irregular intervals; the data from leeches that had been injected with reserpine 10 or more days previously were grouped into blocks for analysis. Between 4 and 16 rescrpinc-injected animals were assayed at each postinjection time interval. In addition, the nervous systems of 73 normal, untreated leeches were assayed for dopamine and serotonin levels with HPLC, glyoxylic acid-induced fluorescence, and neutral red staining.

To examine the acute effects of reserpine on isolated nerve cords, individual chains were placed in a $35 \times 10$-mm petri dish containing $3.3 \mathrm{ml}$ normal saline or saline containing reserpine. Two chains of ganglia were obtained from each of 6 normal leeches, one of midbody ganglia $7-9$, the other of midbody ganglia $10-12$. Because anterior ganglia contain more serotonin than more posterior ganglia (Lent, 1984; B. A. O'Gara, unpublished observations), the chain of ganglia receiving reserpine treatment was alternated between anterior and posterior chains. Each treatment group thus consisted of a total of 6 chains of ganglia: 3 anterior and 3 posterior chains. Reserpine concentrations ranged from $10^{-8}$ to $10^{-3} \mathrm{M}$, and incubation times ranged from 1 to $6 \mathrm{hr}$. Depending on reserpine concentration, glacial acetic acid concentrations in both control and reserpine-containing salines ranged from $0.5 \%$ to $0.000005 \%$ (from highest to lowest reserpine concentration, respectively). Following incubation at room temperature (approximately $21^{\circ} \mathrm{C}$ ), the dopamine and serotonin content of each chain was determined by HPLC. Depletion of serotonin or dopamine in reserpine-treated chains was expressed as a percentage reduction compared to the paired control.

\section{Glyoxylic acid-induced fluorescence}

Amine-containing neurons in the leech nerve cord can be visualized by processing the tissue for glyoxylic acid-induced fluorescence (Lent, 1982). Isolated nerve cords were incubated for $1 \mathrm{hr}$ in a solution composed of $3 \%$ glyoxylic acid, $600 \mathrm{~mm}$ sucrose, and $20 \mathrm{~mm}$ HEPES, adjusted to $\mathrm{pH}$ 7.4 with $\mathrm{NaOH}$ (Ocorr and Berlind, 1983). The nerve cord was then removed from the glyoxylic acid solution, positioned on a slide, and air-dried for $1 \mathrm{hr}$. The slide was subsequently heated at $80-90^{\circ} \mathrm{C}$ for 3 min. Finally, the nerve cords were covered with immersion oil, coverslipped, and viewed with a fluorescence microscope. Reserpine-treated and normal, untreated nerve cords were processed together to ensure identical processing so that comparisons between treatment groups could be made.

\section{Neutral red staining}

Staining with neutral red can be used to visualize amine-containing neurons (Stuart et al., 1974). Isolated nerve cords were placed in normal salinc containing $0.001 \%$ ncutral red until the serotonin-containing neurons in normal nerve cords exhibited intense staining (1-6 hr). The 
unfixed tissue was than examined using a compound microscope. Reserpine-treated and normal, untreated nerve cords were processed together to ensure identical processing.

\section{Behavioral experiments}

The long-term behavioral effects of reserpine treatment were assessed in 6 leeches for $168 \mathrm{~d}$ following a single injection of $100 \mu \mathrm{g}$ reserpine into the crop (body weight of $0.5-4 \mathrm{gm}$ ). Control leeches $(n=6)$ were injected with the identical carrier solution that lacked reserpine. Each leech was housed separately in a 705-ml plastic container (Rubbermaid) containing $500 \mathrm{ml}$ artificial pond water $[1 \mathrm{mM} \mathrm{NaCl}, 13 \mu \mathrm{M} \mathrm{KCl}, 4 \mu \mathrm{M}$ $\mathrm{Ca}\left(\mathrm{NO}_{3}\right) \cdot 4 \mathrm{H}_{2} \mathrm{O}, 17 \mu \mathrm{M} \mathrm{Mg}\left(\mathrm{SO}_{4}\right) \cdot 7 \mathrm{H}_{2} \mathrm{O}, 71 \mu \mathrm{M}$ HEPES buffer]. Both groups of leeches were fed on ox blood $62 \mathrm{~d}$ prior to the start of the experiment and were not fed for the duration of the experiment. Both reserpine-treated and control leeches were tested for biting behavior and swimming activity (see below) every $12 \mathrm{hr}$ through $4 \mathrm{~d}$ postinjection, at $7 \mathrm{~d}$ postinjection, then at $7 \mathrm{~d}$ intervals from 7 to $56 \mathrm{~d}$ postinjection and at $14 \mathrm{~d}$ intervals from 56 to $168 \mathrm{~d}$ postinjection. The experimenters conducting these tests were unaware of the treatment status of the animals. However, once the effects of reserpine became evident, the treatment of each animal was easily discernable. At $170 \mathrm{~d}$ postinjection, midbody ganglia 10-12 were isolated from the leeches, and their serotonin and dopamine contents were determined by HPLC.

Biting assay. To examine the effects of reserpine and various amines on biting behavior, the biting assay of Lent and Dickinson (1984) was utilized. Each leech was placed on a $7.5 \times 10-\mathrm{cm}$ piece of Parafilm M (American National Can, Greenwich, $\mathrm{CI}$ ) lying on a slide warmer maintained at $35^{\circ} \mathrm{C}$. A weighted, inverted bottom of a $60 \times 15-\mathrm{mm}$ plastic petri dish was used to restrict the leech's movements. At the end of a 15-min trial, the outline of the dish was marked by pressing on the petri dish (most bite marks were near the edge of the dish). The leech was removed, and the number of bite marks was counted using a dissection microscope.

The effects of various amines on biting behavior of both normal and reserpine-treated leeches were assayed after bathing the intact leech in pond water containing dissolved amines. Amine neurotransmitters dissolved in pond water are able to alter the behavior of intact leeches (Lent and Dickinson, 1984). Leeches were bathed in pond water containing a known concentration of an amine for $5,10,15$, or $20 \mathrm{~min}$. Biting behavior was then immediately assessed using the biting assay. Attempts to measure an increase of serotonin levels in the nervous system following a 20 -min exposure to $10^{-3} \mathrm{M}$ serotonin in the bath were inconclusive (O'Gara, unpublished observations).

Swimming assay. Swimming was evoked by rapidly transferring the leech and the water in its home container $(500 \mathrm{ml})$ into a $15-\mathrm{cm}$-diameter circular glass container. If the leech clung to the side of its home container, it was gently dislodged with a metal spatula as the water was poured from the home container. The total duration of swimming activity that occurred in the 2 min following transfer was recorded. Swimming activity was defined as the undulation of any portion of the body occurring at a frequency of $0.5-2 \mathrm{~Hz}$ while both suckers were detached from the substrate. The reason for these liberal criteria (as opposed to requiring undulation of the entire body or progress through the water) was that reserpine-treated leeches sometimes initially expressed swimlike undulations of only a few of the anterior segments. Subsequently, the number of segments undulating would increase until the leech was producing relatively normal swimming movements, indicating that the initial movements represented the gradual onset of swimming activity. As with biting behavior, the effects of amines on swimming activity were assayed after bathing intact leeches in pond water containing known amounts of dissolved amines for 5-20 min.

The effects of the amine antagonist cyproheptadine on swimming activity of rescrpinc-trcatcd lecches also were cxamined. First, the swim duration of leeches injected with $100 \mu \mathrm{g}$ reserpine 5-14 d previously was assayed. Each leech was then injected with cyproheptadine (32$320 \mu \mathrm{g} / \mathrm{gm}$ dissolved in distilled water) into the crop. Swim duration was assayed $15 \mathrm{~min}$ after injection and at 30 -min intervals up to 165 min after injection. If equally distributed throughout the body, these amounts of cyproheptadine would produce concentrations ranging from 0.1 to $1 \mathrm{~mm}$. Control leeches were injected with distilled water.

\section{Statistics}

Analysis of variance and subsequent tests between cell means were performed in accordance with Keppel (1973); Wilcoxon and $t$ tests were
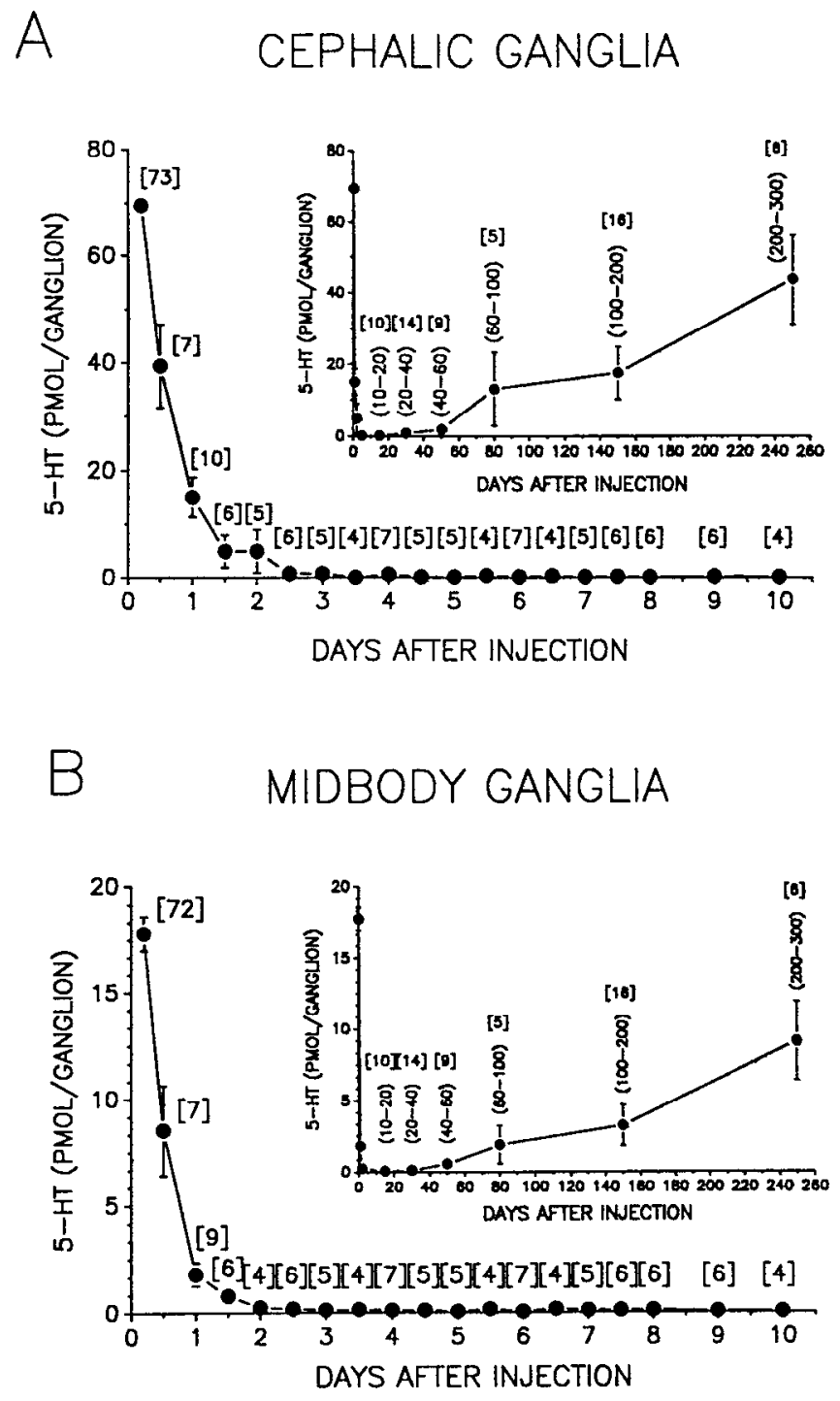

Figure 2. Depletion of serotonin from cephalic ganglia $(A)$ and midbody ganglia $(B)$ induced by injection of $100 \mu \mathrm{g}$ reserpine into crop. Numbers within brackets indicate the number of animals assayed at each time interval. Numbers within parentheses in insets indicate time intervals over which data have been grouped for the indicated point. Insets show changes in serotonin levels over a compressed time scale. In this and other figures, when individual points do not have error bars, the SEM was smaller than the symbol.

performed in accordance with McCall (1975). Data are presented as means \pm SEM.

\section{Results}

Reserpine-induced depletion and subsequent recovery of serotonin and dopamine levels in intact leeches

Reserpine treatment caused a profound and prolonged depletion of both serotonin and dopamine from the nervous system of the intact leech. Serotonin levels fell for 2-3 d after reserpine injection and then reached a plateau that lasted for approximately $30 \mathrm{~d}$ (Fig. 2). In the cephalic ganglia (supraesophageal and subesophageal ganglia), serotonin levels fell from the control value of $69.46 \pm 2.11 \mathrm{pmol} / \mathrm{cephalic}$ ganglia to a mean value of $0.35 \pm 0.05 \mathrm{pmol} / \mathrm{cephalic}$ ganglia during the plateau from 2.5 to $30 \mathrm{~d}$ postinjection (Fig. $2 A$ ). Hence, reserpine caused the elimination of $99.5 \%$ of the total amount of serotonin normally 

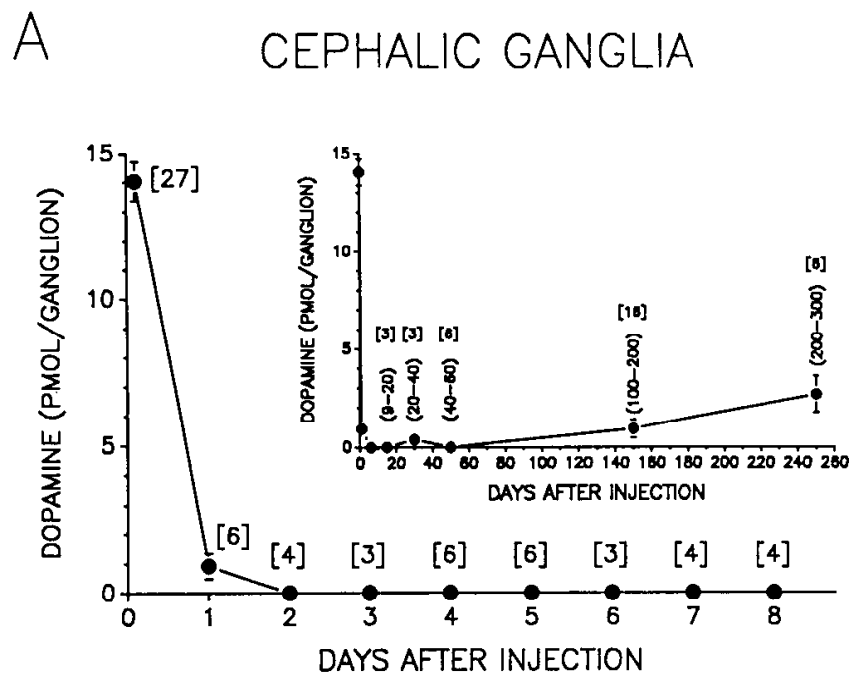

\section{MIDBODY GANGLIA}

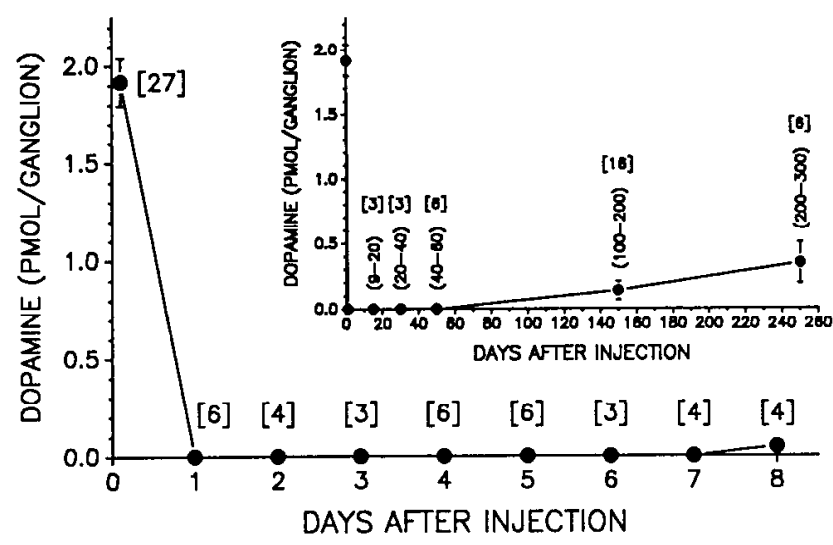

Figure 3. Depletion of dopamine from cephalic ganglia $(A)$ and midbody ganglia $(B)$ induced by injection of $100 \mu \mathrm{g}$ reserpine into crop. Numbers within brackets indicate the number of animals assayed at each time interval. Numbers within parentheses in insets indicate time intervals over which data have been grouped for the indicated point. Insets show changes in dopamine levels over the time course of the experiment. present in the nervous system. In midbody ganglia 10-12, serotonin levels fell from $17.80 \pm 0.81 \mathrm{pmol} / \mathrm{ganglion}$ to a plateau value of $0.12 \pm 0.01 \mathrm{pmol} /$ ganglion (Fig. $2 B$ ), approximately $0.7 \%$ of control levels. Serotonin levels began to recover $30 \mathrm{~d}$ after injection and continued to rise for the duration of the experiment. However, even 9 months after the initial treatment, serotonin levels had still not recovered to control levels (Fig. 2). There was no apparent difference between cephalic and midbody ganglia in the rates of depletion or recovery.

Reserpine treatment also caused dopamine levels in the cephalic ganglia to fall from control values of $14.03 \pm 0.67 \mathrm{pmol} /$ cephalic ganglia to undetectable levels by $2 \mathrm{~d}$ postinjection (Fig. $3 A$ ). Similarly, dopamine levels in midbody ganglia $10-12$ fell from $1.92 \pm 0.12 \mathrm{pmol} /$ ganglion to undetectable levels within $1 \mathrm{~d}$ after injection (Fig. $3 B$ ). Dopamine levels were still profoundly depressed 9 months postinjection; recovery occurred more slowly than serotonin levels (cf. Figs. 2, 3, insets). At the longest time interval examined (200-300 d), serotonin levels had recovered to $50-60 \%$ of control, while dopamine levels had recovered to only $20 \%$ of control. There was no apparent difference between cephalic and midbody ganglia in the rates of dopamine depletion or recovery.

Because the data for these experiments were obtaincd from approximately equal numbers of leeches during each season, the data presented here are not biased by seasonal variations in the levels of either serotonin or dopamine; they thus are presented as means for the entire year.

\section{Histological correlates of reserpine-induced amine depletion}

Although HPLC analysis indicated that reserpine treatment caused a profound depletion of amines, we wished to determine if serotonin was depleted from all serotonin-containing neurons. We found that, in control preparations, staining of the aminecontaining neurons due to either glyoxylic acid-induced fluorescence or neutral red was as previously described (Stuart et al., 1974; Lent, 1982). In each ganglia, we found staining of the paired Retzius cells, paired cells 21 and 61 , and the unpaired posterior medial cell (Fig. 4A-C). [In anterior ganglia, the posterior medial cell occurs as a pair (Fig. $4 E$; Lcnt, 1982).] In addition, glyoxylic acid-induced fluorescence occurred in the neuropil and in axons of the amine-containing neurons (Fig. $4 A, B)$. Reserpine treatment induced a substantial reduction in glyoxylic acid-induced fluorescence and neutral red staining in

Figure 4. Histological correlates of reserpine-induced serotonin depletion. The ganglia in the first 2 columns were processed for glyoxylic acidinduced fluorescence, and those in the third column were stained with neutral red. Photomicrographs in the top row of ganglia were obtained from untreated control leeches. Ganglia in the second and third rows were stained $24 \mathrm{hr}$ following reserpine treatment (second row) or at maximal serotonin depletion (third row). Ganglia in $A, D$, and $G$ are viewed dorsally; all other ganglia in rows $1-3$ are viewed ventrally. The filters used for the fluorescence micrographs did not differentiate between fluorescence duc to scrotonin or dopamine; therefore, some of fluorescence in the neuropil is due to dopamine even though it appears yellow rather than dopamine's normal blue-green fluorescence. However, the physical boundaries of both dopamine and serotonin fluorescence were similar in extent, as were the effects of reserpine on the amounts of their respective fluorophors. In the ganglia from untreated control leeches (top row), there is staining of the Retzius cells, cells 21 and 61 , and the posterior median cell (see $L$ for cell locations). In some neutral red-stained ganglia, the posterior median cell stains very lightly and thus is not clearly visible in $C$; however, in other ganglia, neutral red staining of the posterior median cells is quite evident (arrow in $F$ ). The entire neuropil in ganglia of untreated animals shows glyoxylic acid-induced fluorescence $(A, B)$. Many fluorescent axons were present in the interganglionic connectives $(J)$. One day after reserpine injection (second row), neuropil fluorescence was greatly reduced or eliminated $(D, E)$; however, the somata still exhibit intense fluorescence $(D$, $E$ ) and neutral red staining $(F)$. At maximal amine depletion (row 3), all glyoxylic acid-induced fluorescence was eliminated $(G, H)$. At this time, axons no longer fluoresced after exposure to glyoxylic acid $(K)$; however, background fluorescence was increased as compared to connectives from an untreated leech $(J)$. At maximal amine depletion, neutral red staining is eliminated $(I)$. In ganglia from these animals, as well as some leeches examined during summer, the Retzius cells had associated with them small structures $(I$, arrow), which were apparently microglia. $L$, Schematic diagram of typical midbody ganglion showing the positions of the serotonin-containing somata. Each ganglion contains 7 serotonin-containing somata: 2 Retzius cells $(R z), 2$ cells 21 , two cells 61 , and 1 posterior median cell $(P M)$. Cells 21 are on the dorsal aspect of the ganglion; all of the other serotonin-containing neurons are on the ventral aspect. In anterior ganglia, the postcrior median cell occurs as a pair. Scale bars: $A, 200 \mu \mathrm{m}$ for $A-I ; J, 100 \mu \mathrm{m}$ for $J, K$. 


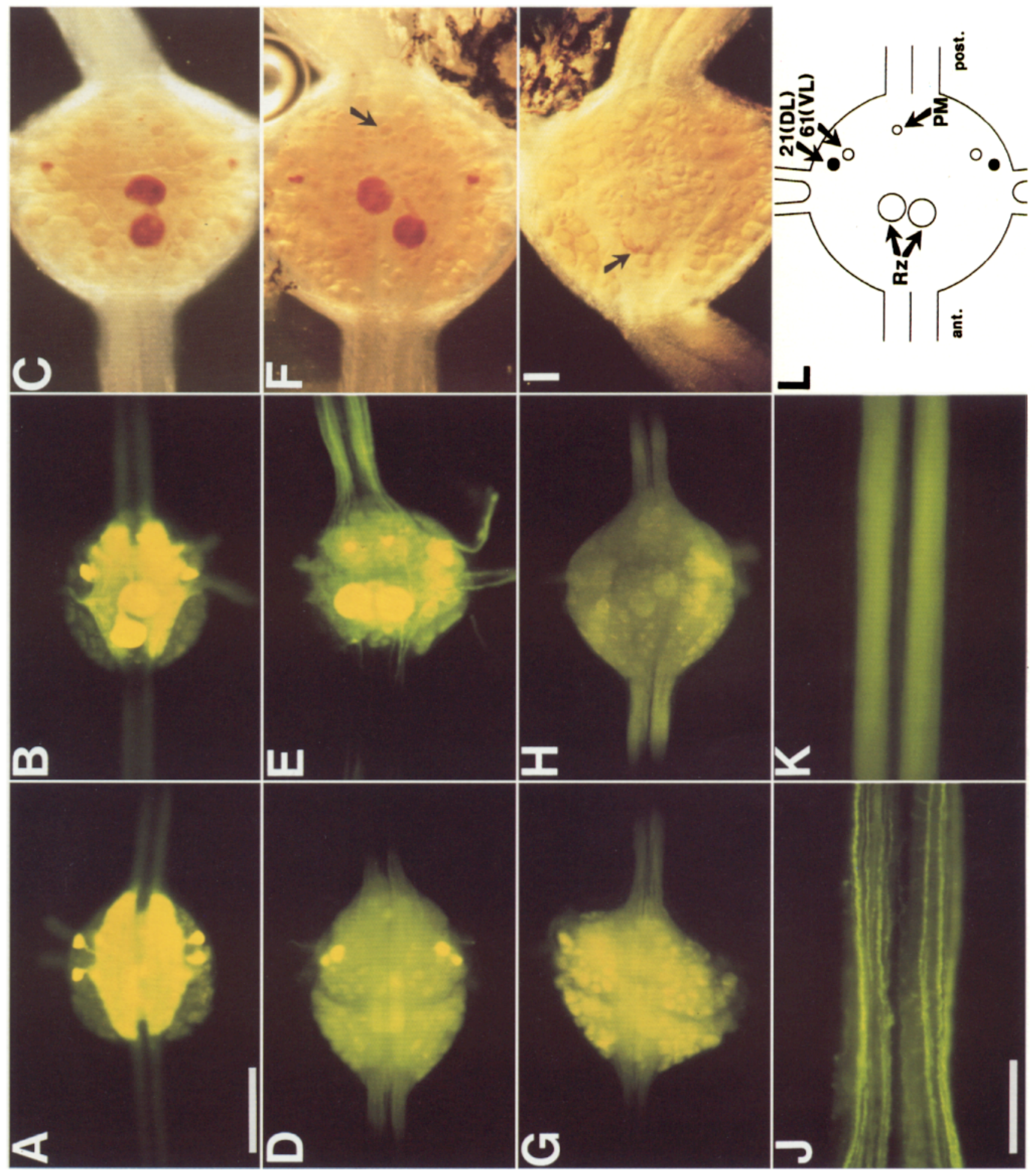




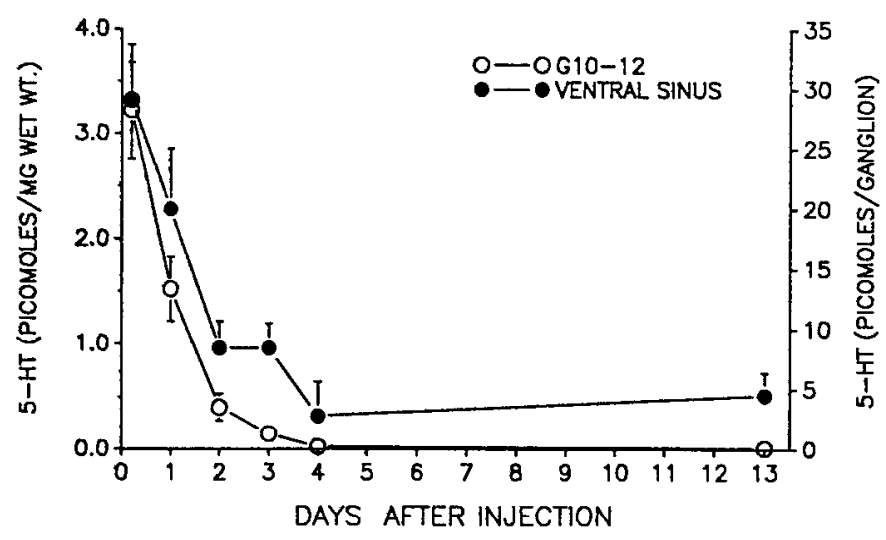

Figure 5. Depletion of serotonin from vasofibrous tissue of ventral blood sinus following reserpine treatment. The ventral blood sinus of segments 10-12 was assayed for serotonin content (left ordinate) following injection of $100 \mu \mathrm{g}$ reserpine into the crop. For comparison of the depletion rate, the serotonin content of midbody ganglia 10-12 (right ordinate) of the same animals is also plotted. Six leeches were assayed to obtain control values: 5 for $1-4 \mathrm{~d}$ after injection, 4 at $13 \mathrm{~d}$ after injection. Error bars represent SEM.

the serotonin-containing neurons (Fig. $4 D-K$ ). The intensity of staining produced by glyoxylic acid and neutral red during reserpine-induced depletion of amines closely paralleled amine levels as measured by HPLC. By $12 \mathrm{hr}$ after reserpine injection into intact leeches, glyoxylic acid-induced fluorescence was markedly reduced in the neuropil, connectives, and peripheral nerves. By $1 \mathrm{~d}$ postinjection, fluorescence was usually present only in the serotonin-containing somata at an intensity not obviously different from control somata (Fig. $4 D-F$ ). Within 2-3 d after reserpine injection, all fluorescence was absent (Fig. $4 G-$ $I, K)$; however, background fluorescence was elevated compared to untreated controls. As amine levels recovered over an interval of weeks to months, fluorescence was first noted in the somata, and only at later intervals was fluorescence present in the neuropil and extraganglionic processes.

Neutral red did not stain the neuropil and neuronal processes well enough to allow the same detailed observation of reserpineinduced depletion as allowed by glyoxylic acid-induced fluorescence. However, the pattern of staining of the serotonincontaining somata by neutral red was usually similar to that produced by glyoxylic acid-induced fluorescence in ganglia obtained from a given leech. There were 2 exceptions to this parallel course of staining: As noted above, neutral red showed an obvious seasonal variation in the intensity of staining the Retzius cells that was not as evident with glyoxylic acid-induced fluorescence. A second difference in staining intensity occurred in several leeches 2-3 d following reserpine treatment. In these preparations, neutral red staining was indistinguishable from controls, even though both HPLC and glyoxylic acid-induced fluorescence indicated that only very low levels of amines were present.

\section{Serotonin content of the vasofibrous tissue of the ventral blood sinus}

Vasofibrous tissue accumulates and metabolizes serotonin (Coggeshall and Yaksta-Sauerland, 1974; Lent, 1984). Following serotonin depletion induced by $5,7-\mathrm{DHT}$, the serotonin content of the vasofibrous tissue is increased, apparently due to interference with the metabolism of serotonin within the vasofibrous tissue, rather than by increasing serotonin uptake (Lent, 1984). We found that, in contrast to 5,7-DHT treatment, reserpine treatment caused a decrease in the serotonin content of the vasofibrous tissue of the ventral blood sinus (Fig. 5). The depletion of serotonin from both the vasofibrous tissue and the nerve cord occurred at similar rates.

\section{General observations on the behavioral effects of reserpine}

Leeches treated with reserpine exhibited grossly abnormal behavior within 1-2 d postinjection. The animals were inactive and were less responsive to stimuli than normal leeches. With sufficient prodding, the animals did swim; however, the initial swimming movements usually appeared stiff. With continued swimming, the movements became more normal in appearance and were sometimes indistinguishable from the swimming movements of untreated, control leeches. Isolated nerve cords from reserpine-treated leeches usually did not generate swimming activity; however, bath application of $50 \mu \mathrm{M}$ serotonin restored the expression of normal swimming activity. In 9 of 11 isolated nerve cord preparations from reserpine-treated leeches, no swimming activity was seen following stimulation of the dorsal posterior (DP) nerve or the swim-gating neuron cell 204 (both methods are normally very effective in eliciting swimming activity). In one preparation, stimulation of the DP nerve evoked swimming for several minutes after dissection, but eventually became ineffective. In another preparation, strong stimulation of the swim-gating neuron cell 204, but not DP nerve stimulation, evoked swimming activity. Serotonin application facilitated expression of swimming activity in both preparations. Reserpine-treated leeches often did not respond to stimuli that would terminate swimming in untreated leeches. For example, when untreated leeches make contact with the sides of their container, they usually stop swimming and attach their anterior sucker to the container side. However, reserpinetreated leeches were much less likely to stop swimming following contact with the walls of their container. In addition, reserpinetreated leeches sometimes continued to generate swimming movements after attaching their front sucker to the side of the container. This contrasts with untreated leeches, which immediately cease swimming movements upon front sucker attachment. Unlike untreated leeches, reserpine-treated leeches sometimes protruded their jaws while swimming. Reserpine-treated leeches also show the following abnormal behaviors: dorsalventral flattening, increased body wall tonus, erected annuli, reduced sucker attachment, reduced exploratory movements of the head, and occasional swimming movements while being held.

\section{Effect of reserpine on biting behavior}

Because biting behavior is dependent on CNS serotonin levels (Lent and Dickinson, 1984), we decided to examine the effects of reserpine on biting. When the biting behavior of control and reserpine-treated leeches was examined, an ANOVA and subsequent Tukey test indicated that reserpine treatment significantly reduced biting behavior by $2 \mathrm{~d}$ after injection and completely eliminated biting behavior by $4 \mathrm{~d}$ postinjection (Fig. $6 \mathrm{~A}$ ). Biting behavior remained significantly depressed up to $139 \mathrm{~d}$ postinjection (Fig. $6 \mathrm{~B}$ ). The ANOVA indicated significant effects due to reserpine injection ( $p<0.001 ; F=25.28$; df $=1,10$ ), time after reserpine injection $(p<0.001 ; F=4.65 ; \mathrm{df}=23,230)$, and the interaction $(p<0.001 ; F=3.66 ; \mathrm{df}=23,230)$. Even though biting behavior of reserpine-injected leeches was not 
$A$
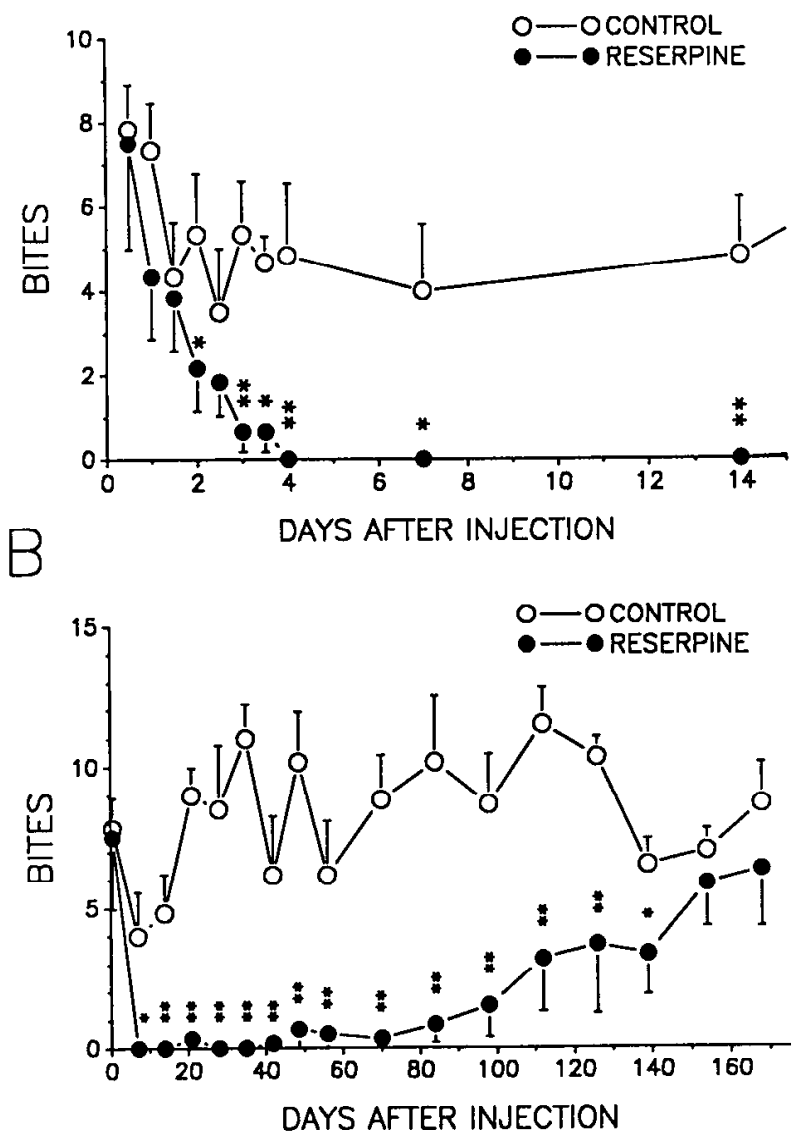

Figure 6. Elimination of biting behavior by injection of $100 \mu \mathrm{g}$ reserpine into crop. The numbers of bites during 15 -min trials are plotted for the first $14 \mathrm{~d}$ following reserpine injection $(A)$ and for the entire 168$\mathrm{d}$ course of the experiment $(B)$. Control leeches showed a decrease in the number of bites they produced when they were repeatedly tested with a 12-hr intertrial interval. This decrease in biting behavior was apparently reversed when longer intertrial intervals were used $(B)$. This decrease in biting behavior, at least superficially, resembles habituation; however, we have not formally studied this decrease to determine if it in fact is due to habituation. Biting behavior was eliminated within 4 $\mathrm{d}$ of reserpine injection and remained significantly depressed until 139 $\mathrm{d}$ postinjection. Some early points $(0.5-14 \mathrm{~d})$ from $A$ are omitted in $B$ for clarity. Asterisks indicate when control and reserpine-injected groups were significantly different: ${ }^{*}, p<0.05 ;^{* *}, p<0.01$. Error bars represent SEM.

significantly different from controls at the end of the experiment (168 d postinjection), both the serotonin and dopamine levels in the ventral nerve cords of reserpine-treated leeches were still significantly depressed. At $170 \mathrm{~d}$ after injection, serotonin content of the controls was $55.94 \pm 5.30 \mathrm{pmol} /$ ganglion, whereas ganglia from reserpine-treated leeches contained $6.81 \pm 3.08$ $\mathrm{pmol} /$ ganglion $(p<0.001 ; t=8.02 ; \mathrm{df}=10)$. The dopamine content of ganglia from control leeches was $1.72 \pm 0.11 \mathrm{pmol} /$ ganglion and $0.31 \pm 0.16 \mathrm{pmol} /$ ganglion from reserpine-injected leeches $(p<0.001 ; t=7.26 ; \mathrm{df}=10)$.

\section{Effects of amines on biting behavior}

Control leeches. Lent and Dickinson (1984) reported that depletion of serotonin from the nervous system by 5,7-DHT eliminated leech biting behavior, and that bathing these treated leeches in serotonin could restore biting behavior. However, they found
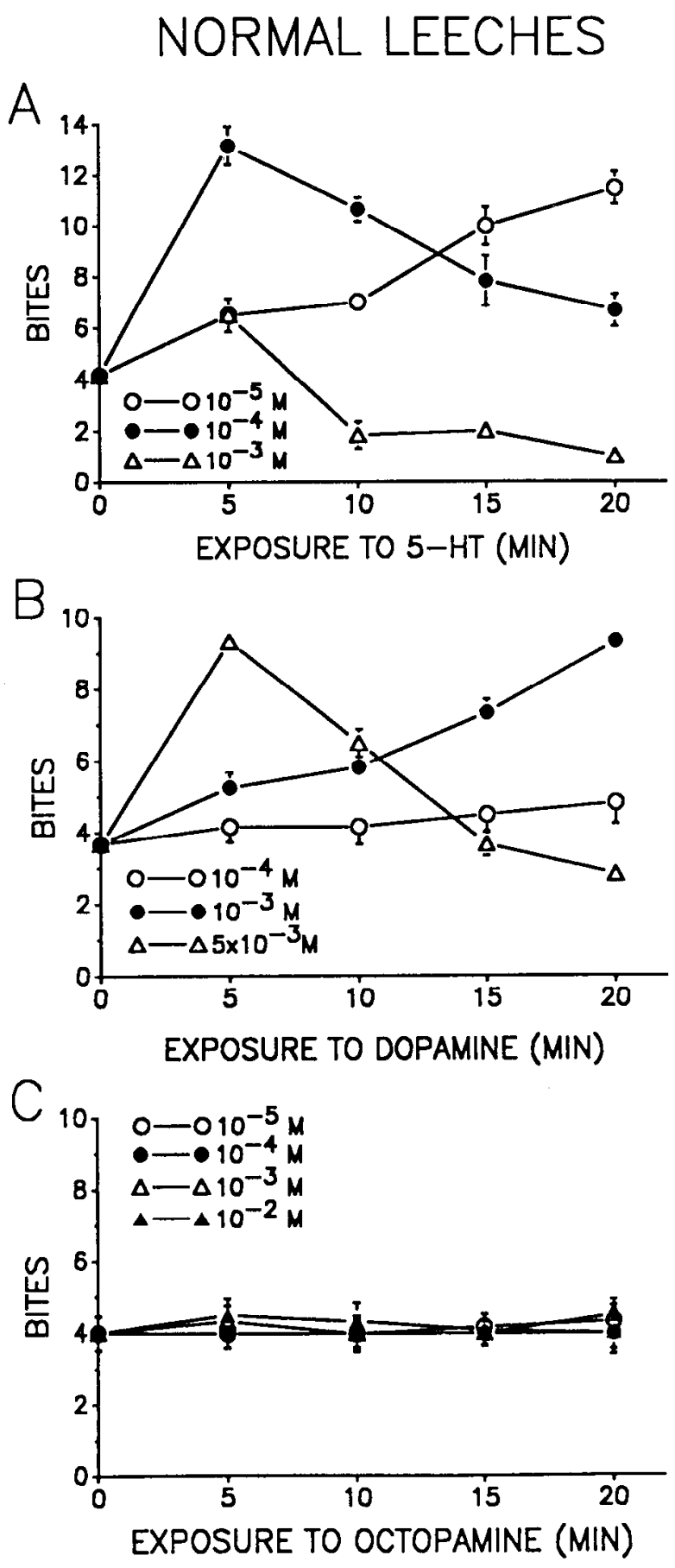

Figure 7. Modulation of biting activity in control leeches with bathapplied amines. The effects on biting behavior of bathing normal leeches (not injected with reserpine) in pond water containing serotonin $(A)$, dopamine $(B)$, or octopamine $(C)$ are shown. Serotonin and dopamine produced increased biting behavior at low concentrations or short exposure times. At higher concentrations, smaller increases or inhibition of biting occurred [as compared to controls (exposure time $=0$ )]. Octopamine had no effect on biting. The ordinate is the number of bites per 15-min trial. The abscissa is the duration of exposure to bath-applied amine prior to trial. Error bars represent SEM.

that exposure of untreated control animals to serotonin had complex results; high concentrations of serotonin in the bath or long exposure times actually decreased biting behavior below control levels. To further investigate these anecdotal results, we 


\section{RESERPINE-TREATED LEECHES}
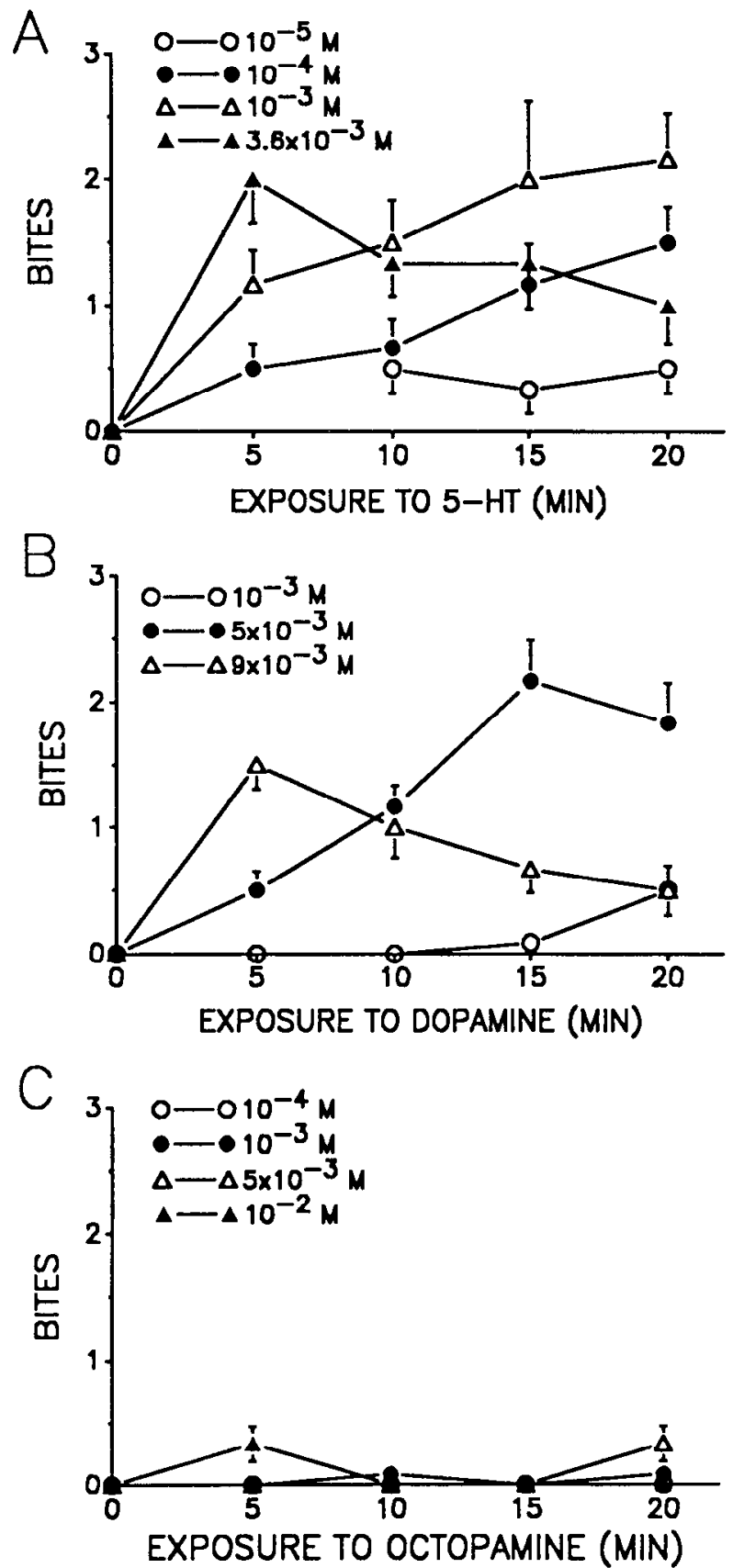

Figure 8. Restoration of biting activity in reserpine-treated leeches by bath exposure to serotonin or dopamine, but not octopamine. The effects on biting behavior of bathing reserpine-treated leeches in pond water containing serotonin $(A)$, dopamine $(B)$, or octopamine $(C)$ are shown. The effects of these amines were qualitatively similar to those seen in normal leeches (Fig. 7). The ordinate is the number of bites per $15-\mathrm{min}$ trial, and the abscissa is the duration of exposure to bath-applied amine prior to the trial. Error bars represent SEM.

performed quantitative experiments to describe the effects of bath application of amine neurotransmitters on the biting behavior of normal control leeches. We tested the effects of various concentrations and exposure times of bath-applied serotonin, dopamine, and octopamine on biting behavior. Bath exposure to $10^{-5} \mathrm{M}$ serotonin (Fig. $7 \mathrm{~A}$ ) elicited progressively greater num-
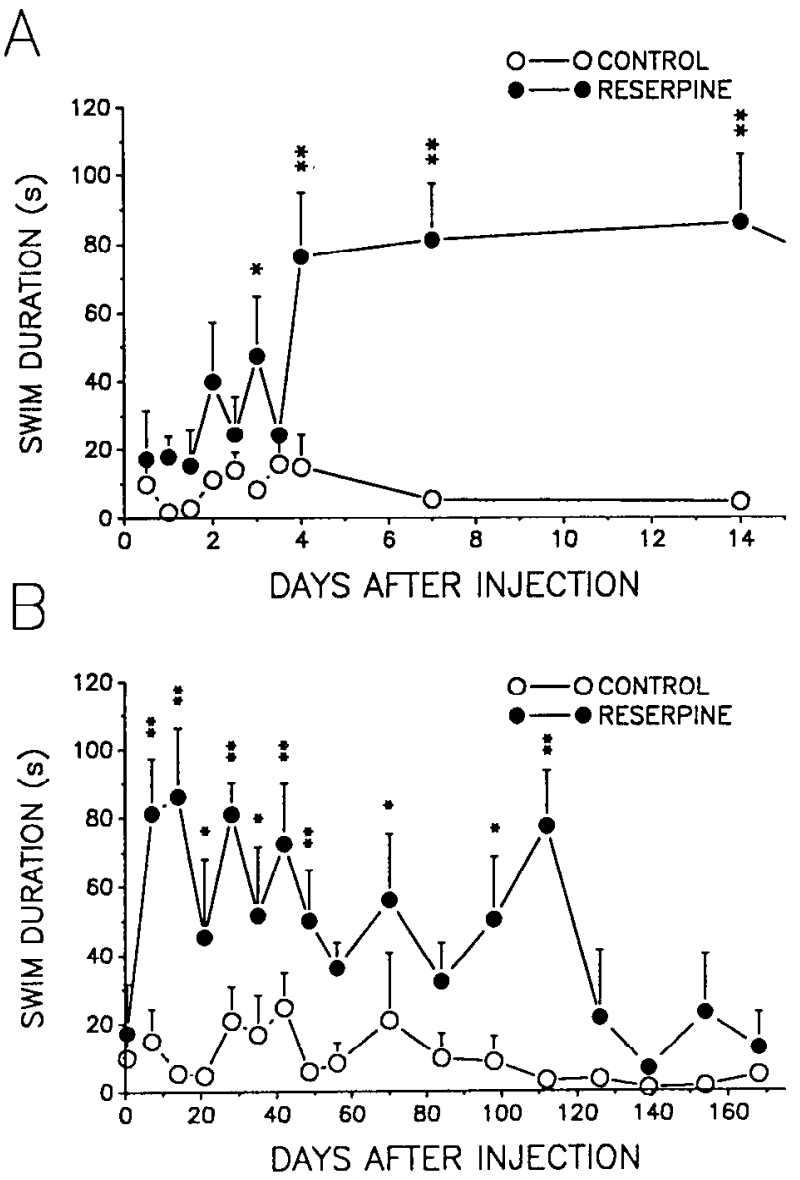

Figure 9. Swim duration was increased following reserpine treatment. Swimming was evoked by transferring the leech from one container to another. The amount of time the leech spent swimming in the following 2 min was recorded. Swim duration first became significantly different $3 \mathrm{~d}$ following reserpine injection $(A)$ and remained significantly greater up to $112 \mathrm{~d}$ postinjection $(B)$. Some early points from $A(0.5-7 \mathrm{~d})$ are omitted in $B$ for clarity. Asterisks indicate when control and reserpineinjected groups were significantly different: ${ }^{*}, p<0.05 ;{ }^{* *}, p<0.01$, Error bars represent SEM.

bers of bites with increased exposure times [as compared to animals not exposed to serotonin (exposure time of $0 \mathrm{~min}$ )]. At a higher serotonin concentration $\left(10^{-4} \mathrm{M}\right)$, a 5 -min exposure time produced a large increase in the number of bites. However, with longer exposure times, the increase in the number of bites was smaller than produced by a 5 -min exposure. At even higher serotonin concentrations $\left(10^{-3} \mathrm{M}\right)$, biting activity was reduced below control levels following exposure times of $10 \mathrm{~min}$ or longer. Bath application of dopamine (Fig. 7B) evoked qualitatively similar results; however, much higher concentrations of dopamine were required to elicit similar effects. Bath application of octopamine (Fig. 7C) had no discernable effect on the biting activity of normal leeches.

Reserpine-treated leeches. We next determined if the reduction of biting behavior produced by reserpine could be reversed by bathing reserpine-treated leeches in the amines serotonin, dopamine, or octopamine. We found that exposure to serotonin or dopamine, but not octopamine, restored biting behavior (Fig. 8). The effects of serotonin and dopamine on reserpine-treated leeches were qualitatively similar to those in normal leeches. At the lower serotonin and dopamine concentrations, the number of bites increased with increasingly longer exposure times (Fig. 
$8 A, B)$. At the highest concentrations utilized in these experiments, the largest increase in biting occurred at a 5-min exposure time. However, with longer exposure times, the increases in the number of bites were smaller than caused by a 5 -min exposure. As was true of untreated leeches, exposure to serotonin was more effective than dopamine exposure. There were 2 quantitative differences between the effects of these amines on reserpine-treated versus untreated leeches: First, the maximum number of bites produced by reserpine-treated leeches exposed to either amine was lower than that found in untreated controls. Second, higher amine concentrations were required for reserpine-treated leeches than controls. For example, in normal, control leeches, exposure to $10^{-5} \mathrm{M}$ serotonin caused easily discernable increases in biting behavior (Fig. $7 A$ ). However, when reserpine-treated leeches were exposed to $10^{-5} \mathrm{M}$ serotonin, little increase in biting activity was observed (Fig. 8A).

\section{Effects of reserpine treatment on swimming activity}

The expression of swimming activity is dependent on the levels of serotonin in the CNS (Willard, 1981; Glover and Kramer, 1982). Because acute treatment with reserpine abolishes swimming activity in isolated nerve cords (Hashemzadeh-Gargari and Friesen, 1989), we expected that reserpine treatment would also reduce swimming activity of intact leeches. To test this expectation, we studied the long-term effects of reserpine treatment on swimming activity in the same animals used to study the effects of reserpine on biting behavior. Unexpectedly, we found that the duration of swimming activity was longer in reserpine-treated animals than in controls (Fig. 9). An ANOVA and subsequent Tukey test indicated that the increase in swim duration first became significant $3 \mathrm{~d}$ after reserpine injection and remained significantly different (with the exception of a few points) up to $112 \mathrm{~d}$ after injection. The ANOVA indicated significant effects due to reserpine injection $(p<0.001 ; F-45.03$; $\mathrm{df}=1,10)$, time since reserpine injection $(p<0.001 ; F=3.19$; $\mathrm{df}=23,230)$, and the interaction $(p<0.025 ; F=1.80 ; \mathrm{df}=$ 23,230 ). As was true of biting behavior, swim duration returned to control values, whereas serotonin and dopamine levels remained significantly depressed $170 \mathrm{~d}$ after reserpine injection.

Attempts to reverse the reserpine-induced increase in swim duration by bathing reserpine-treated leeches in various amines were unsuccessful. Bath application of $10 \mu \mathrm{M}$ serotonin (not shown) or $1 \mathrm{~mm}$ serotonin, dopamine, octopamine, or histamine did not alter the swim duration of reserpine-treated leeches (Fig. $10 A)$.

\section{Effects of cyproheptadine on the swimming activity of reserpine-treated leeches}

The reduction of neuronal amine levels induced by reserpine treatment is due to inhibition of storage mechanisms; however, the synthesis of amines continues (Slotkin, 1974). It is possible that the ability of reserpine-treated leeches to swim is dependent on these low levels of residual amines still present in the nerve cord. To determine if the swimming activity of reserpine-treated leeches was dependent on residual amines, we used the amine antagonist cyproheptadine to eliminate the effects of any residual amines. We found that cyproheptadine treatment caused dose-dependent decreases of swim duration (Fig. 10B). At high cyproheptadine doses ( 160 and $320 \mu \mathrm{g} / \mathrm{gm}$ ), swimming activity was completely eliminated. Thus, the ability of reserpine-treated leeches to generate swimming movements was apparently de-
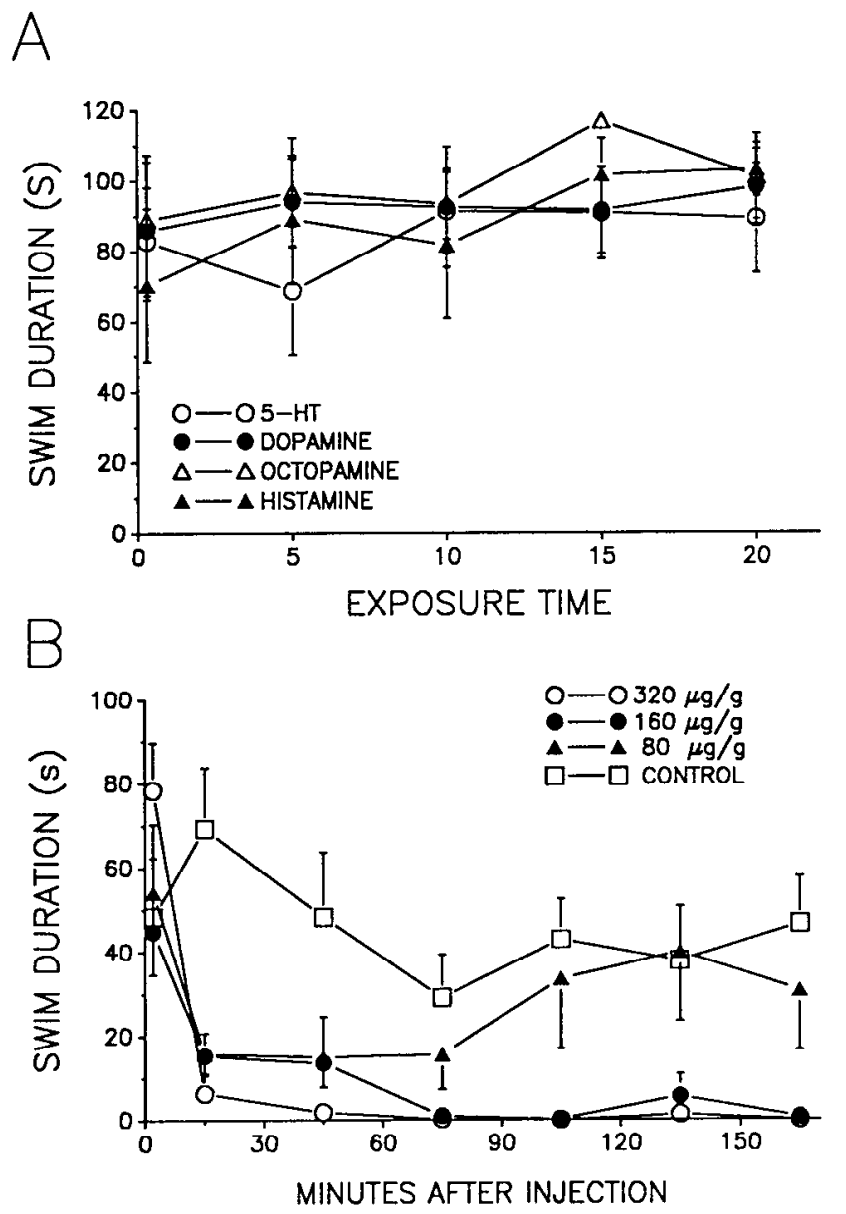

Figure 10. Effects of amines and cyproheptadine on reserpine-induced increase in swim duration. $A$, Amine treatment did not reduce swim duration to normal levels. The effects of reserpine injection on swim duration were not reversed by bathing reserpine-treated leeches in pond water containing $1 \mathrm{~mm}$ serotonin, dopamine, octopamine, or histamine. $B$, Elimination of swimming activity by the amine antagonist cyproheptadine. Cyproheptadine produced a dose-dependent reduction of swim duration and eliminated swimming at high concentrations. The number of leeches used in the $320-\mu \mathrm{g} / \mathrm{gm}$ group was 10 , whereas in all other groups, 6 leeches were used. In addition, another group of 6 leeches was tested after being injected with $32 \mu \mathrm{g} / \mathrm{gm}$ cyproheptadine, but was not plotted for clarity. All points for this group fell well within the SEM (error bars) of the control group.

pendent on the low levels of residual amines still present in the animal.

\section{Depletion of amines from isolated nerve cords following acute exposure to reserpine}

Hashemzadeh-Gargari and Friesen (1989) reported that acute exposure of isolated nerve cords to $10-150 \mu \mathrm{M}$ reserpine abolishes swimming activity within $4 \mathrm{hr}$. It was therefore of interest to determine the extent of amine depletion caused by acute cxposure to reserpine under similar conditions. We found that exposure to $10 \mu \mathrm{M}$ reserpine induced a time-dependent depletion of both serotonin and dopamine (Fig. 11A). During a 4-hr incubation, serotonin was reduced by $23.4 \pm 5.7 \%$, and dopamine was reduced by $31.7 \pm 2.5 \%$. After $6 \mathrm{hr}$ incubation in $10 \mu \mathrm{M}$ reserpine, serotonin was reduced by $31.0 \pm 4.5 \%$, and dopamine was reduced by $34.1 \pm 2.5 \%$. A series of Wilcoxon tests indicated that significant depletion of both serotonin and dopamine 

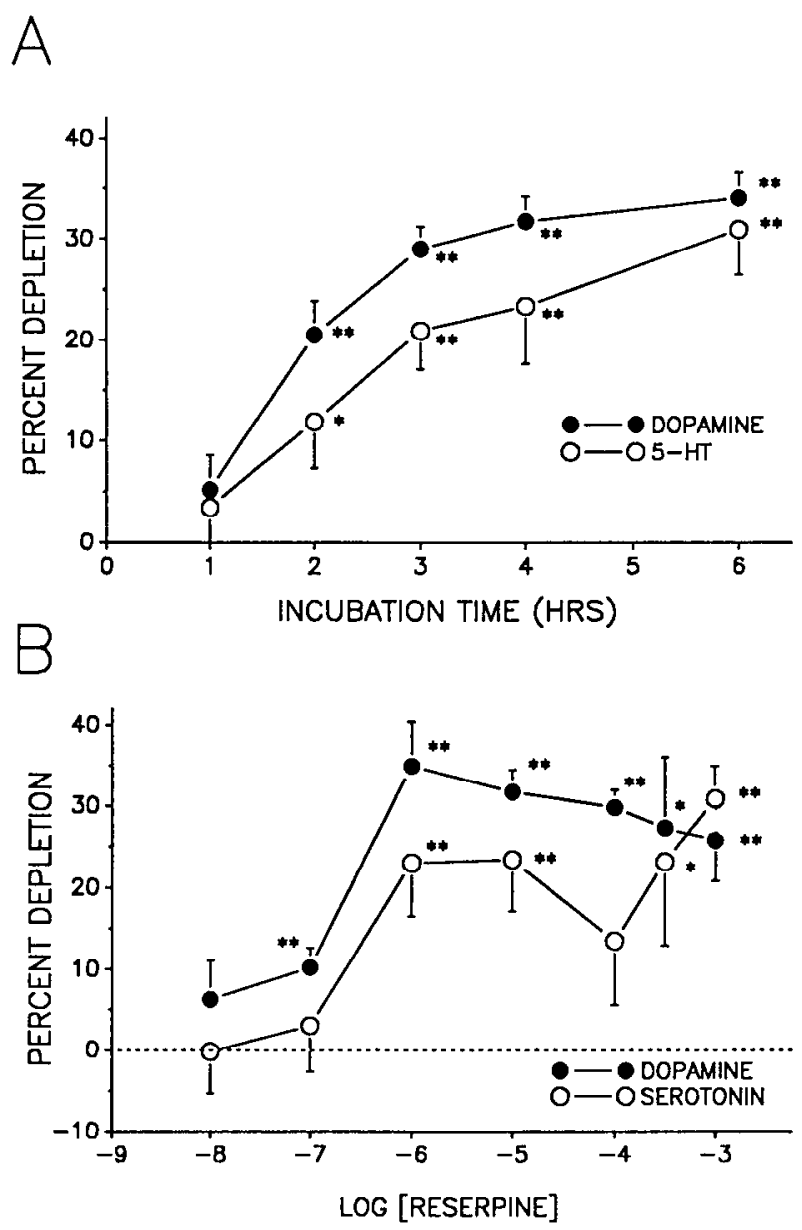

Figure 11. Depletion of serotonin and dopamine by acute exposure of isolated ganglia to reserpine. $A$, Depletion induced by $10 \mu \mathrm{M}$ reserpine with incubation durations of $1-6 \mathrm{hr}$. $B$, Depletion induced by $4 \mathrm{hr}$ incubation in reserpine concentrations ranging from $10^{-8}$ to $10^{-3} \mathrm{M}$. Indicated significance levels $\left({ }^{*}, p<0.05 ;{ }^{* *}, p<0.025\right)$ were determined using a directional Wilcoxon test of the data for each point as compared to untreated chains of ganglia from the same animals (not shown). Error bars represent SEM.

occurred with incubation times of $2 \mathrm{hr}$ or longer. Reserpineinduced amine depletion was initially more rapid during incubation times ranging from 0 to $3 \mathrm{hr}(7-10 \%$ per hr) than during incubation times of 3-6 hr (1-3\% per hr; Fig. 11A).

In another set of experiments, significant depletion of both dopamine and serotonin occurred when the concentration of reserpine was varicd with a constant 4-hr incubation period (Fig. 11B). Maximal depletion of serotonin (30.9 $\pm 4.0 \%$ ) occurred at $10^{-3} \mathrm{M}$, and maximal depletion of dopamine $(34.9 \pm$ $5.5 \%$ ) occurred at $10^{-6} \mathrm{M}$. A series of Wilcoxon tests indicated that significant depletion of dopamine occurred at reserpine concentrations of $10^{-7} \mathrm{M}$ or higher. Serotonin was significantly depleted at reserpine concentrations of $10^{-6} \mathrm{M}$ or higher, except for $10^{-4} \mathrm{M}$. Isolated nerve cords acutely exposed to 10 or 100 $\mu_{\mathrm{M}}$ reserpine for $4 \mathrm{hr}$ did not have obviously reduced glyoxylic acid-induced fluorescence as compared to controls (not shown).

\section{Discussion}

Biogenic amines are known to modify the expression of motor activity in both vertebrates (Grillner, 1986; Grillner et al., 1986) and invertebrates (Willard, 1981; Kravitz, 1988; Marder and
Meyrand, 1989). Although the effects of a particular neurotransmitter on a given type of behavior (e.g., locomotion or feeding) may differ in disparate species, the general mechanisms by which neuromodulators cause alterations in neuronal function are probably universal. Reserpine-induced amine depletion had wide-ranging effects on leech behavior, indicating the great importance of amines to normal nervous system function. Our development of a technique whereby amines are easily and reliably depleted from the leech CNS will allow the examination of the actions of these amines. Following depletion, amine levels may be precisely controlled by their replacement in the experimental saline.

\section{Depletion of amines by reserpine injection}

A 100- $\mu$ g injection of reserpine into the leech crop caused depletion of serotonin and dopamine to less than $1 \%$ of normal levels (Figs. 2, 3). Serotonin and dopamine levels then remained maximally depressed for approximately 1 month following injection of reserpine (Figs. 2, 3). This dosage of reserpine produced similar levels of amine depletion regardless of body weight or nutritional status of the leech. These results suggest that, at a dosage of $100 \mu \mathrm{g} / \mathrm{leech}$, all reserpine binding sites have become saturated (Giachetti and Shore, 1978). Saturation of reserpine binding sites is also suggested by the acute exposure experiments shown in Figure $11 B$, where reserpine concentrations above 1 $\mu \mathrm{m}$ produced little increase in amine depletion. The concentration of reserpine in leeches receiving 100- $\mu \mathrm{g}$ injections of reserpine (40-165 $\mu \mathrm{M}$ if equally distributed throughout the body) would be higher than the concentration apparently producing saturation during direct acute exposure of the nervous system. Although we were not able to demonstrate reserpine-induced octopamine depletion due to technical limitations, such depletion was demonstrated in 2 other leech species (Webb and Orchard, 1980).

Although recovery from reserpine treatment is a relatively slow process in all species, recovery in the leech seems especially slow. Following the initial depletion, amine levels showed very little recovery for approximately 1 month (Figs. 2, 3). Amine levels then recovered very slowly, and at 200-300 d following reserpine injection, serotonin levels were only at $50-60 \%$ of control levels, while dopamine was at $20 \%$ of control levels. In some mammalian preparations, complete recovery of amine levels can occur in less than 1 week (Carlsson et al., 1963; Dahlström and Häggendal, 1969). Even after chronic reserpine treatment, some recovery of amine levels in mammals is visible within 1 week, with a return to near normal levels taking $1-2$ months (Häggendal and Lindqvist, 1964). In other invertebrates, recovery from reserpine-induced amine depletion is slow compared to mammals, but is faster than in the leech. In the cockroach, recovery of amine levels was visible within 1 week of reserpine treatment; amine levels were normal in 2-4 weeks (Sloley and Owen, 1982). Octopus shows a slower rate of recovery than the cockroach, but recovery is visible $16 \mathrm{~d}$ after reserpine administration, though the time necessary for complete recovery is unknown (Juorio and Killick, 1972). One reason for the relatively slow rates of depletion and recovery of amines in the leech may be that the reserpine was injected into the leech crop, an organ designed for long-term storage of blood obtained through feeding. Reserpine may be slowly released from the crop over a prolonged time span. Reserpine produces amine depletion through irreversible binding to the amine translocator on storage organelles; recovery is dependent on the syn- 
thesis of new organelles (Slotkin, 1974). Thus, another plausible explanation for the slow recovery of amine levels is that leeches may synthesize new storage organelles at an unusually slow rate (Slotkin, 1974).

\section{Histological correlates of reserpine-induced amine depletion}

Depletion of amines was clearly indicated by glyoxylic acidinduced fluorescence and neutral red staining; both of these methods showed decreases in staining intensity following reserpine treatment (Fig. 4) that closely paralleled HPLC-determined serotonin and dopamine levels (Figs. 2, 3). However, there were 2 differences between the 2 methods of staining: First, the intensity of neutral red staining more closely reflected the seasonal variation of serotonin levels. Second, intense neutral red staining was occasionally still present $2-3 \mathrm{~d}$ after the leech was injected with reserpine, whereas glyoxylic acid-induced fluorescence was always eliminated at this time. These differences may be due to the fact that neutral red and glyoxylic acidinduced fluorescence produce "staining" through different mechanisms. Glyoxylic acid reacts with the amine molecule itself to produce a fluorophor (Moore and Loy, 1978). The physical basis for the staining of amine-containing cells by neutral red is unclear, but it has been suggested that neutral red binds to amine binding sites and receptors (Nemes et al., 1979). This suggests that the cellular element stained by neutral red is at least somewhat independent of the amine content of the neuron. Our finding that neutral red staining could still be quite intense when serotonin levels have been depleted to quite low levels by reserpine indicates that neutral red staining is not an infallible indicator of amine content in the stained cells.

\section{General effects of reserpine on behavior}

Reserpine treatment caused drastic alterations of many behaviors of the medicinal leech. As is true of many other animals, reserpine-treated leeches are inactive and hyporesponsive. Reserpine-induced hyporesponsiveness or sedation has been noted in mammals (Häggendal and Lindqvist, 1963; Brodie et al., 1966; Häggendal et al., 1967), insects (Robertson, 1976; Sloley and Owen, 1982; Murdock et al., 1985; Brookhart et al., 1987), and molluses (Juorio, 1971; Juorio and Killick, 1972). Reserpine-treated leeches had increased body wall tonus, and their movements were stiff and unnatural, probably due to serotonin depletion. Serotonin causes relaxation of leech body wall muscles and thus would produce reduced body wall tonus (Mason and Kristan, 1982). In addition, serotonin increases the relaxation rate of body wall muscles following muscle contraction. Hence, leeches with reduced serotonin levels would be expected to have increased body wall tonus and to have difficulty producing rapid alterations in muscle tension.

The roles of dopamine and octopamine in the control of leech behavior are largely unknown. In addition, the effects of amine depletion on other neurotransmitter systems is unknown. Octopamine is able to induce swimming activity in leeches as well as locomotion in other invertebrates (Kinnamon et al., 1984; Sombati and Hoyle, 1984; Belanger and Orchard, 1988; Hashemzadeh-Gargari and Friesen, 1989). Although both octopamine and serotonin can induce swimming in the leech, these amines do not always have similar actions because, in several other invertebrate systems, serotonin and octopamine have opposite actions (Kravitz et al., 1980; Horvitz et al., 1982). The role of dopamine in invertebrates is largely unknown; however, the importance of dopaminergic systems in mammalian motor control is well documented (Yurek and Sladek, 1990).

\section{Effects of reserpine treatment on biting behavior}

Biting behavior was restored to reserpine-treated leeches by bathing them in pond water containing serotonin or dopamine, but not octopamine (Fig. 8). However, in both reserpine-treated and normal leeches, bath application of serotonin or dopamine at a high concentration or for a long exposure time produced smaller increases in biting behavior than lower concentrations and, in fact, sometimes produced inhibition of biting behavior below control levels (Figs. 7, 8). Our observation of a biphasic effect of serotonin on biting behavior of normal leeches (Fig. 7) closely parallels the results of Lent and Dickinson (1984). In contrast to our results (Figs. 7, 8), Lent and Dickinson (1984) were not able to demonstrate an augmentation of biting behavior utilizing $30 \mu \mathrm{M}$ dopamine. However, in our experiments, much higher dopamine concentrations, approaching $1 \mathrm{~mm}$, did produce an augmentation of biting (Fig. $7 B$ ). At present, it is unclear why high concentrations of serotonin and dopamine (or long exposure times) result in decreased biting behavior. Two general mechanisms for these effects are easily imagined: First, high amine concentrations (or long exposure times) could produce receptor desensitization whereby the amine-induced excitatory drive for biting behavior would be lost as desensitization occurred. Second, biting behavior could be under both excitatory and inhibitory control. At low amine concentrations (or short exposure times), only the excitatory control may be activated, while at higher concentrations (or long exposure times), the inhibitory control could be activated as well.

It has been suggested that serotonin functions generally to modulate feeding in many diverse phyla (Lent et al., 1989). Although serotonin is important in many different feeding systems, the specific actions of serotonin are not identical in all systems. Some similarity of the role of amines in regulating feeding behavior in leeches and blowflies is suggested by the finding that reserpine reduces the responsiveness of leeches (Fig. 6) and blowflies to food stimuli (Murdock et al., 1985; Brookhart et al., 1987). However, the effects of amine neurotransmitters on feeding are not identical in blowflies and leeches. Reserpine induces hyperphagia in blowflies when offered highly stimulating food (Murdock et al., 1985). This is in contrast to leeches, where higher serotonin levels cause increased meal size (Lent et al., 1988). There are several other differences between the regulation of feeding by amines in leeches and blowflies. In the leech, both serotonin and dopamine, but not octopamine, increase biting behavior (Figs. 2, 3). In contrast, octopamine increases, whereas serotonin and dopamine decrease, the responsiveness of blowflies to food stimuli (Long and Murdock, 1983; Long et al., 1986). Even within the insects, the role of particular amines may vary; for example, depletion of serotonin by 5,7DHT reduces the size of meals in the blood-sucking insect $R$ hodnius (Cook and Orchard, 1989).

Both dopamine and serotonin increased biting behavior in the leech; however, the effect of serotonin occurred at concentrations 1-2 orders of magnitude lower than that of dopamine (Fig. 7). Similarly, the effects of serotonin on the Retzius cells are known to occur at concentrations 1-2 orders of magnitude lower than dopamine (Sunderland and Leake, 1980). Whether the effects of each amine are mediated through specific serotonin and dopamine receptors is unclear; however, it has been sug- 
gested that serotonin and dopamine act on the same amine receptor in leech Retzius cells (Sunderland and Leake, 1980).

\section{Effects of reserpine treatment on swimming activity}

Because either acute (Hashemzadeh-Gargari and Friesen, 1989) or chronic reserpine treatment eliminates the expression of swimming activity in isolated nerve cords, we expected that reserpine treatment would eliminate swimming from intact animals. Unexpectedly, reserpine treatment increased the duration of swim episodes evoked by the sensory stimulation caused by transferring a leech to a new container (Fig. 9). This finding raises 2 questions: First, if swimming activity is dependent on high serotonin levels as suggested by Willard (1981) and Glover and Kramer (1982), how are reserpine-treated leeches able to swim at all, given the almost complete depletion of serotonin? Second, given that reserpine-treated leeches can swim, why do they swim more than controls?

The effect of reserpine on swim duration was not reversed by bathing the leeches in serotonin, dopamine, octopamine, or histamine (Fig. 10A). This is perhaps not surprising because both serotonin and octopamine have been shown to have stimulatory effects on swimming activity (Willard, 1981; Glover and Kramer, 1982; Belanger and Orchard, 1988; Hashemzadeh-Gargari and Friesen, 1989). These excitatory effects may have been further augmented by the development of receptor supersensitivity in the amine-depleted animals. However, the fact that higher concentrations of serotonin or dopamine were necessary to induce biting behavior in reserpine-treated than in normal leeches (Figs. 7,8 ) argues against receplor supersensitivity as a causative factor in the increased swim duration of reserpine-treated leeches. It remains possible that these amines may also have inhibitory effects on swimming activity, and that the excitatory effect predominates under our testing conditions.

The reduction of amine levels induced by reserpine is due to inhibition of storage mechanisms; however, amine synthesis still continues (Slotkin, 1974). The ability of reserpine-treated leeches to swim was apparently due to the very low level of residual amines still present in the nerve cord. When the actions of the residual amines were blocked in intact reserpine-treated leeches by the amine antagonist cyproheptadine, swimming activity was eliminated (Fig. 10B). This hypothesis is strengthened by the finding that isolated nerve cords from reserpine-treated leeches do not express swimming activity, apparently because the residual amines diffuse from the nerve cord until they are lowered below an effective concentration (O'Gara et al., 1989). Thus, it appears that not only do amines facilitate the expression of swimming activity, but that swimming activity cannot occur unless amines are present in the nervous system in sufficient concentrations.

Even if the hypothesis that swimming activity of reserpinetreated leeches is dependent on residual amines is correct, an explanation of why these leeches swim more than normal is still lacking. One possibility is that reserpine treatment produces a loss of inhibitory control over swimming. This is suggested by the observation that reserpine-treated leeches often do not stop swimming when exposed to stimuli that stop swimming in normal leeches. Inhibitory control over swimming by the cephalic ganglia has been demonstrated (Brodfuehrer and Friesen, 1986; O'Gara and Friesen, 1987), though the mechanisms producing this inhibitory control are unknown.

\section{Reserpine-induced amine depletion from isolated nerve cords}

Acute exposure of isolated nerve cords to reserpine demonstrated both concentration and time dependence of dopamine and serotonin depletion (Fig. 11). The threshold concentration of reserpine necessary to produce amine depletion was between 0.1 and $1 \mu \mathrm{M}$ (Fig. 11B); however, little additional depletion was evident at reserpine concentrations above $1 \mu \mathrm{M}$ (Fig. 11B), suggesting that the reserpine binding sites saturate at about 1 $\mu \mathrm{M}$ (Giachetti and Shore, 1978). Reserpine-induced amine depletion appears to be most rapid at initial exposure, rather than during longer incubation times (Fig. 11A). This reduction in depletion rate may reflect the ability of reserpine to deplete a small labile pool during the first few hours and a larger, physiologically inert pool at longer time intervals (Carlsson, 1964; Giarman et al., 1964). Changes in the small labile pool are apparently responsible for changes in neural function following reserpine treatment (Häggendal and Lindqvist, 1964). This would explain the results of Hashemzadeh-Gargari and Friesen (1989), who found that a 4-hr reserpine treatment abolished swimming activity from isolated leech nerve cords even though serotonin levels, as determined here, were only depleted by approximately $25 \%$.

We have developed an easy, reliable method for inducing a profound and prolonged depletion of amine neurotransmitters from the nervous system of the leech through a single injection of reserpine. Amine levels were depleted to less than $1 \%$ of normal for a period exceeding 1 month. Biting behavior was eliminated by reserpine treatment and could be restored by treatment with serotonin or dopamine but not octopamine. In contrast to biting behavior, reserpine treatment increased the duration of swimming evoked by sensory stimuli. This increase was not reversed by amine treatment, but swimming was eliminated by the amine antagonist cyproheptadine, suggesting that swimming was dependent on residual amines in the nerve cord following reserpine treatment. The fact that reserpine-treated leeches swam more than normal suggests that amines also have a role in the inhibition of swimming activity.

\section{References}

Belanger JH, Orchard I (1986) Leydig cells: octopaminergic neurons in the leech. Brain Res 382:387-391.

Belanger JH, Orchard I (1988) Release of octopamine by Leydig cells in the central nervous system of the leech Macrobdella decora, and its possible neurohormonal role. J Comp Physiol A 162:405-412.

Brodfuehrer PD, Friesen WO (1986) Control of leech swimming activity by the cephalic ganglia. J Neurobiol 17:697-705.

Brodie BB, Comer MS, Costa E, Dlabac A (1966) The role of brain serotonin in the mechanism of the central action of reserpine. J Pharmacol Exp Ther 152:340-349.

Brookhart GL, Edgecomb RS, Murdock LL (1987) Amphetamine and reserpine deplete brain biogenic amines and alter blow fly feeding behavior. J Neurochem 48:1307-1315.

Carlsson A (1964) Functional significance of drug-induced changes in brain monoamine levels. Prog Brain Res 8:9-27.

Carlsson A, Jonasson J, Rosengren E (1963) Time correlation between the effects of reserpine on behavior and storage mechanism for arylalkylamines. Acta Physiol Scand 59:474-477.

Coggeshall RE, Yaksta-Sauerland BA (1974) The localization of 5-hydroxytryptamine in chromaffin cells of the Ieech body wall. $J$ Comp Neurol 156:459-470.

Cook H, Orchard I (1989) 5,7-Dihydroxytryptamine affects feeding behaviour, serotonin-like immunoreactivity and serotonin content of selected tissues in Rhodnius prolixus. Soc Neurosci Abstr 15:738.

Dahlström A, Häggendal J (1969) Recovery of noradrenaline in ad- 
renergic axons of rat sciatic nerves after reserpine treatment. J Pharm Pharmacol 21:633-638.

Friesen WO, Cometa AK, Hashemzadeh H (1988) Serotonin modifies synaptic transmission in neuronal circuits of the leech (Hirudo medicinalis). Soc Neurosci Abstr 14:384.

Giachetti A, Shore PA (1978) The reserpine receptor. Life Sci 23:8992.

Giarman NJ, Freedman DX, Schanberg SM (1964) Drug-induced changes in the subcellular distribution of serotonin in rat brain with special reference to the action of reserpine. Prog Brain Res 80:72-80.

Glover JC, Kramer AP (1982) Serotonin analog selectively ablates identified neurons in the leech embryo. Science 216:317-319.

Grillner S (1986) The effect of L-dopa on the spinal cord-relation to locomotion and the half center hypothesis. In: Neurobiology of vertebrate locomotion (Grillner S, Stein PSG, Stuart DG, Forssberg H, Herman RM, eds.), pp 269-277. London: MacMillan.

Grillner S, Brodin L, Sigvardt K, Dale N (1986) On the spinal network generating locomotion in the lamprey: transmitters, membrane properties and circuitry. In: Neurobiology of vertebrate locomotion (Grillner S, Stein PSG, Stuart DG, Forssberg H, Herman RM, eds), pp 335-352. London: MacMillan.

Häggendal J, Lindqvist M (1963) Behaviour and monoamine levels during long-term administration of reserpine to rabbits. Acta Physiol Scand 57:431-436.

Häggendal J, Lindqvist M (1964) Disclosure of labile monoamine fractions in brain and their correlation to behaviour. Acta Physiol Scand 60:351-357.

Häggendal J, Lindqvist M, Roos B-E (1967) Further studies on monoamine metabolism and behaviour in rabbits chronically treated with reserpine. Acta Physiol Scand 69:95-101.

Hashemzadeh-Gargari H, Friesen WO (1989) Modulation of swimming activity in the medicinal leech by serotonin and octopamine. Comp Biochem Physiol 94C:295-302.

Horvitz HR, Chalfie M, Trent C, Sulston JE, Evans PD (1982) Serotonin and octopamine in the nematode Caenorhabditis elegans. Science 216:1012-1014.

Johnson RG Jr (1988) Accumulation of biological amines into chromaffin granules: a model for hormone and neurotransmitter transport. Physiol Rev 68:232-307.

Juorio AV (1971) Catecholamine and 5-hydroxytryptamine in nervous tissue of cephalopods. J Physiol (Lond) 216:213-226.

Juorio AV, Killick SW (1972) The effect of drugs on the synthesis and storage of monoamines in nervous tissues of molluscs. Int $\mathbf{J}$ Neurosci 4:195-202.

Keppel G (1973) Design and analysis: a researcher's handbook. Englewood Cliffs, NJ: Prentice-Hall.

Kinnamon SC, Klaassen LW, Kammer AE, Claassen D (1984) Octopamine and chlordimeform enhance sensory responsiveness and production of the flight motor pattern in developing and adult moths. J Neurobiol 15:283-293.

Kravitz EA (1988) Hormonal control of behavior: amines and the biasing of behavioral output in lobsters. Science 241:1775-1781.

Kravitz EA, Glusman S, Harris-Warrick RM, Livingstonc MS, Schwarz T, Goy MF (1980) Amines and a peptide as neurohormones in lobsters: actions on neuromuscular preparations and preliminary behavioural studies. J Exp Biol 89:159-175.

Lent CM (1982) Fluorescent properties of monoamine neurons following glyoxylic acid treatment of intact leech ganglia. Histochemistry 75:77-89.

Lent CM (1984) Quantitative effects of a neurotoxin upon serotonin levels within tissue compartments of the medicinal leech. J Neurobiol 15:309-323

Lent CM (1985) Serotonergic modulation of the feeding behavior of the medicinal leech. Brain Res Bull 14:643-655.

Lent CM, Dickinson MH (1984) Serotonin integrates the feeding behavior of the medicinal leech. J Comp Physiol A 154:457-471.

Lent CM, Ono J, Keyser KT, Karten HJ (1979) Identification of serotonin within vital-stained neurons from leech ganglia. J Neurochem 32:1559-1563.

Lent CM, Mueller RL, Haycock DA (1983) Chromatographic and histochemical identification of dopamine within an identified neuron in the leech nervous system. J Neurochem 41:481-490.

Lent CM, Fliegner KH, Freedman E, Dickinson MH (1988) Ingestive behaviour and physiology of the medicinal leech. J Exp Biol 137: 513-527.
Lent CM, Dickinson MH, Marshall CG (1989) Serotonin and leech feeding behavior: obligatory neuromodulation. Am Zool 29:12411254.

Long TF, Murdock LL (1983) Stimulation of blowfly feeding behavior by octopaminergic drugs. Proc Natl Acad Sci USA 80:4159-4163.

Long TF, Edgecomb RS, Murdock LL (1986) Effects of substituted phenylethylamines on blowfly feeding behavior. Comp Biochem Physiol 83C:201-209.

Marder E, Meyrand P (1989) Chemical modulation of an oscillatory neural circuit. In: Neuronal and cellular oscillators (Jacklet JW, ed), pp 317-338. New York: Marcel Dekker.

Marsden CA, Kerkut GA (1969) Fluorescent microscopy of the 5HTand catecholamine-containing cells in the central nervous system of the leech Hirudo medicinalis. Comp Biochem Physiol 31:851-862.

Mason A, Kristan WB Jr (1982) Neuronal excitation, inhibition and modulation of leech longitudinal muscle. J Comp Physiol A 146:527536.

McCall RB (1975) Fundamental statistics for psychology, 2d ed. New York: Harcourt Brace Jovanovich.

Moore RY, Loy R (1978) Fluorescence histochemistry. In: Neuroanatomical research techniques (Robertson RT, ed), pp 115-139. New York: Academic.

Murdock LL, Brookhart G, Edgecomb RS, Long TF, Sudlow L (1985) Do plants "psychomanipulate" insects? In: Bioregulators for pest control (Hedin PA, ed), pp 337-351. Washington, DC: American Chemical Society.

Nemes Z, Dietz R, Luth JB, Gomba S, Hackenthal E, Gross F (1979) The pharmacological relevance of vital staining with neutral red. Experientia 35:1475-1476.

Nusbaum MP (1986) Synaptic basis of swim initiation in the leech. III. Synaptic effects of serotonin-containing interneurones (cells 21 and 61) on swim CPG neurones (cells 18 and 208). J Exp Biol 122: 303-321.

Nusbaum MP, Kristan WB Jr (1986) Swim initiation in the leech by serotonin-containing interneurones, cells 21 and 61. J Exp Biol 122: 277-302.

Ocorr KA, Berlind A (1983) The identification and localization of a catecholamine in the motor neurons of the lobster cardiac ganglion. J Neurobiol 14:51-59.

O'Gara BA, Friesen WO (1987) Termination of swimming activity by stimulation of a neuron in subesophageal ganglion of the leech, Hirudo medicinalis. Soc Neurosci Abstr 13:1060.

O'Gara BA, Friesen WO (1988) Reserpine depletes serotonin from the CNS of the leech (Hirudo medicinalis) and drastically alters behavior. Soc Neurosci Abstr 14:383.

O'Gara BA, Chae H, Friesen WO (1989) Aminergic neurotransmitters reverse the effect of reserpine on biting behavior but not swimming activity in the leech Hirudo medicinalis. Soc Neurosci Abstr 15:27.

Robertson HA (1976) Octopamine, dopamine and noradrenaline content of the brain of the locust, Schistocerca gregaria. Experientia 32: 552-554.

Shore PA (1962) Release of serotonin and catecholamines by drugs. Pharmacol Rev 14:531-550.

Sloley BD, Owen MD (1982) The effects of reserpine on amine concentrations in the nervous system of the cockroach (Periplaneta americana). Insect Biochem 12:469-476.

Slotkin TA (1974) Reserpine. In: Neuropoisons: their pathophysiological actions, Vol 2, Poisons of plant origin (Simpson LL, Curtis DR, eds), pp 1-60. New York: Plenum.

Sombati S, Hoyle G (1984) Generation of specific behaviors in a locust by local release into neuropil of the natural neuromodulator octopamine. J Neurobiol 15:481-506.

Stenzel K, Neuhoff V (1976) Tryptophane metabolism and the occurrence of amino acids and serotonin in the leech (Hirudo medicinalis) nervous system. J Neurosci Res 2:1-9.

Stuart AE, Hudspeth AJ, Hall ZW (1974) Vital staining of specific monoamine-containing cells in the leech nervous system. Cell Tissue Res 153:55-61.

Sunderland AJ, Leake LD (1980) Evidence for an amine receptor on the Retzius cells of the leeches Hirudo medicinalis and Haemopis sanguisuga. Comp Biochem Physiol 67C:159-166.

Webb RA, Orchard I (1980) Octopamine in leeches. I. Distribution of octopamine in Macrobdella decora and Erpobdella octoculata. Comp Biochem Physiol 67C:135-140.

Willard AL (1981) Effects of serotonin on the generation of the motor 
program for swimming by the medicinal leech. J Neurosci 1:936944.

Yurek DM, Sladek JR (1990) Dopamine cell replacement: Parkinson's disease. Annu Rev Neurosci 13:415-440.
Zallakian M, Knoth J, Metropoulos GE, Njus D (1982) Multiple effects of reserpine on chromaffin-granule membranes. Biochemistry 21:10511055 . 